Federal Reserve Bank of Dallas

Globalization and Monetary Policy Institute

Working Paper No. 40

http://www.dallasfed.org/assets/documents/institute/wpapers/2009/0040.pdf

\title{
Business Cycles and Remittances: Can the Beveridge-Nelson Decomposition Provide New Evidence?*
}

\author{
Roberto A. Coronado \\ Federal Reserve Bank of Dallas
}

October 2009

\begin{abstract}
In this paper, I analyze the business cycle properties of remittances and output series for three pairs of countries: the United States-Mexico, the United States-El Salvador, and Germany-Turkey. Using an unobserved components state-space model (via the BeveridgeNelson decomposition), I decompose the remittances and output series into stochastic permanent and cyclical components. I then use the resulting stationary cyclical components to estimate co-movements between remittances and output series. Empirical results indicate that remittances are counter-cyclical with all the home countries: Mexico, El Salvador, and Turkey. With respect to source countries, remittances to Mexico are counter-cyclical with the United States business cycle, while remittances from the United States to El Salvador and remittances from Germany to Turkey are strongly pro-cyclical with output fluctuations in the source country. The contribution of this paper to the literature is twofold: (1) I use highfrequency data (quarterly) for a relatively long period of time; and (2) I employ more recent and sophisticated econometric techniques in the decomposition of the series into stochastic permanent and cyclical components. The existing literature lacks both of these important aspects of my analysis. I show that once both of these factors are incorporated into the analysis, empirical results are more aligned to those predicted by economic theory.
\end{abstract}

JEL codes: E32, F24, C22

\footnotetext{
* Roberto A. Coronado, El Paso Branch, Federal Reserve Bank of Dallas, 301 East Main Street, El Paso, TX, 79901. roberto.coronado@dal.frb.org. 915-521-5235. The author is grateful to Chris Murray, Dietrich Vollrath, and David Papell for advice and encouragement. The views expressed in this paper are those of the author and do not necessarily reflect the views of the Federal Reserve Bank of Dallas or the Federal Reserve System..
} 


\section{Introduction}

Remittances are money sent by foreign workers to their home-country. In 2007, remittances reached almost $\$ 320$ billion dollars worldwide [Ratha and $\mathrm{Xu}, 2008$ ]. Roughly 75 percent of total remittances are channeled to developing economies such as India, Turkey, Mexico, Pakistan, and El Salvador. Remittances recently became a major source of income for many of these developing countries, surpassing export income and foreign direct investment. As a result, economists are devoting more attention to these money flows and to their potential economic impacts. ${ }^{1}$

From a theoretical point of view, remittances should be pro-cyclical with the source or host country (i.e. the United States or Germany). With respect to the home country, there is no straight forward prediction given that the migrant faces two opposing forces when deciding whether to remit: altruism vs. self-interest. Therefore, remittances can either be pro- or countercyclical with the recipient or home country (i.e. Mexico, El Salvador, or Turkey). Unfortunately, there are just a few studies that analyze remittance flows and business cycles. Furthermore, most of the existing research on this subject provides ambiguous and inconclusive empirical results.

In 2008, Mexico received more than \$25 billion dollars in remittance income from the United States which represents 2.8 percent of Mexico's gross domestic product and about one-half of Mexico's crude oil exports. Similarly, El Salvador received close to $\$ 3.8$ billion dollars in remittance income accounting for 17 percent of the national output. Turkey, on the other hand, received $€ 820$ million Euros in remittances, from its migrants in Germany, which represent roughly 2.5 percent of the Turkish economy. Mexico, El Salvador, and Turkey are ideal candidates to test whether remittances are pro- or counter-cyclical to output, in both source and home countries, not only because of the increasing importance of remittances on their individual economies, but also because we have a good historical and high-frequency dataset available. In addition, such a dataset provides the researcher with several business cycle fluctuations not only in the receiving countries, but also in the sending countries.

Most of the previous studies on remittances and business cycles concentrate on country-pairs (source and recipient) that typically do not observe a great degree of economic synchronization,

\footnotetext{
${ }^{1}$ Most studies find that remittances help smooth consumption, alleviate poverty and reduce income inequality, increase schooling and investment in entrepreneurial activities, as well as help develop the financial sector (for a comprehensive summary of the importance of remittances to the Mexican, El Salvadorian, and Turkish economies see Section 2).
} 
such as Germany and Turkey, the United States and El Salvador, and the United States and Dominican Republic. Given the strong economic synchronization that exists between the United States and Mexico, analyzing remittances and business cycles between these two countries will imply a more complex economic relationship. ${ }^{2}$ For instance, currently both the United States and Mexico are experiencing economic contractions, and as a result, we should expect remittances to decline (U.S. business cycle downturn), but at the same time we might expect remittances to increase (Mexico business cycle downturn). Latest data releases show that Mexico's remittances from the United States are declining. Therefore, it will prove useful to carefully study which force will dominate the performance of remittances.

I use an unobserved components state-space model (via the Beveridge-Nelson decomposition methodology) to decompose the remittance and output time series into stochastic trend and cyclical components. Practically all of the previous studies on this subject rely on filters (i.e. Polynomial filter, Baxter-King filter, Hodrick-Prescott filter, Christiano-Fitzgerald filter, etc.) to extract the cyclical component out of the time series. It has been well documented in the macroeconomic business cycle literature that such filters typically do not do a good job at decomposing the series into permanent and cyclical components. There is no reason to suspect that this is not the case for the remittance and output series in other countries. ${ }^{3}$

Therefore, I employ a more recent and more accepted econometric technique among the business cycle literature. Using an unobserved components state-space model, I extract the stationary cyclical component of the time series and then use the cyclical components to ask whether remittances to Mexico, El Salvador, and Turkey behave pro- or counter-cyclically with output in both receiving and source economies. Results indicate that remittances are countercyclical with the receiving economies: Mexico, El Salvador, and Turkey. With respect to the source countries, remittances to Mexico are counter-cyclical with U.S. output, while remittances to El Salvador are pro-cyclical with the U.S. economy, and remittances to Turkey are procyclical with Germany's output. The contribution of this paper to the literature is twofold: (1) I use high-frequency data (quarterly) for a relatively long period of time; and (2) I employ more

\footnotetext{
${ }^{2}$ For more detail on economic synchronization between Mexico and the United States, see Cuadra [2008] and Chiquiar and Ramos-Francia [2004 \& 2008].

${ }^{3}$ Murray [2003] documents that the Baxter-King [1997] filter, and in general any band-pass filter, does not isolate the cycle in an unobserved components model with a stochastic trend. Therefore, such filter provides spurious cyclical component for the U.S. output. Cogley and Nason [1995] provide similar empirical results for the HodrickPrescott band-pass filter.
} 
recent and sophisticated econometric techniques in the decomposition of the series into stochastic permanent and cyclical components. The existing literature lacks both of these important aspects of my analysis. I show that once both of these factors are incorporated into the analysis, empirical results are more aligned to those predicted by economic theory.

This paper is organized as follows. The next section presents a brief summary of the importance of remittances to the Mexican, El Salvadorian, and Turkish economies. Section 3 summarizes the main theoretical implications of remittances and the links to the source and home country economies. Previous studies on remittances and business cycle analysis are summarized in Section 4. The econometric model is presented in Section 5. Then, Section 6 discusses the data used in the analysis. Section 7 documents the empirical results. Concluding remarks and suggestions for future research are offered in Section 8.

\section{Economic importance of remittances to Mexico, El Salvador and Turkey}

In 2008, Mexico received \$25 billion in remittances from Mexican workers in the United States, representing roughly 3 percent of Mexico's output and 135 percent of Mexico's foreign direct investment. Furthermore, remittances represent roughly 10 percent of Mexico's total exports, 60 percent of oil exports, and 12 percent of manufacturing exports (see Table 1). For those states in Mexico that are the main sources of migrants to the Unites States, such as Michoacán and Zacatecas, remittances represent as much as 15-20 percent of gross state product. Therefore, remittances are not only an important source of foreign exchange but also are a crucial part of household income in certain areas of Mexico.

El Salvador is by far the country that receives the most remittances as a share of GDP. In 2008, remittances reached roughly $\$ 3.8$ billion dollars and accounted for 17.1 percent of El Salvadorian output. For El Salvador, remittances have been a significant source of income since the early 1990s. For instance, in 1991, remittances accounted for almost 15 percent of GDP. Furthermore, remittances today represent 57 percent of foreign direct investment, 83 percent of total exports, almost 200 percent of manufacturing exports, and 39 percent of total imports. Without doubt, remittance flows to El Salvador constitute a major source of income (see Table 1). 
Turkey received $\$ 1.209$ billion dollars in remittances in 2007 representing 0.2 percent of Turkish GDP. ${ }^{4}$ However, historically, remittances represent a bigger share of Turkish output. For instance, for the period 1970-2000 remittances represented on average 2.2 percent of Turkish GDP. In 2000, Turkey received roughly $\$ 4.5$ billion dollar in remittances from its workers abroad. Such significant amount represents 16.4 percent of Turkish total exports and 8.4 percent of its total imports (see Table 1).

Given that remittances have become a major source of income for many developing countries including the ones analyzed in this paper, there is a relatively abundant and fast-growing economics literature on remittances. Most of these studies concentrate on the economic impacts that such flows have on receiving or home countries. In particular, there is a growing body of research on the impact that remittances have on schooling, poverty and inequality, and financial development, just to name a few. In the following paragraphs, I will briefly summarize such research body. ${ }^{5}$

The impact of remittances on education is of particular importance given the role remittances may play on economic development. Overall the consensus from the existing research body indicates that remittances help increase schooling levels in receiving countries. Lopez Cordova [2004], using a cross-section of all Mexican municipalities in the year 2000, shows that an increase in the fraction of households receiving remittance income is correlated with better schooling, health indicators, and with reductions in poverty rates. Hanson and Woodruff [2003] examine the relationship between household migration behavior and educational attainment in Mexico. Their preliminary empirical findings suggest that children in migrant households complete significantly more years of schooling because sending migrants abroad may generate remittances that in turn raise household income and allow children to complete more schooling. Contrary to Hanson and Woodruff, Borraz [2005], employing census data, finds a positive but small effect of remittances on schooling; particularly, such impact is only for children living in cities with fewer than 2,500 inhabitants and with mothers with low level of education. Cox Edwards and Ureta [2003] find that remittances have a large and significant effect on school retention in El Salvador, particularly in poor areas. Similarly, Acosta et al [2007a] finds that

\footnotetext{
${ }^{4}$ Please note that on Table 1, I report total remittances received by Turkey and their economic significance for the Turkish economy. However, I use remittances from Germany to Turkey throughout the analysis presented here. On average from 1971 to 2008, remittances from Germany account for one-third of overall remittances received by Turkey.

${ }^{5}$ For a comprehensive literature review of the economic impacts of remittances, see Orrenius et al [2009].
} 
while remittances tend to have a positive effect on education in eleven countries in Latin America including Mexico and El Salvador, this impact is often restricted to specific groups of the population, namely low-income households.

Another body of research regarding remittances as an economic development engine is with respect to its impact in reducing poverty and inequality. Esquivel and Huerta-Pineda [2007] investigate the effect of remittances on poverty conditions among Mexican households. Using a propensity score approach, they find that receiving remittances reduces the household's probability of being in poverty between 6.3 and 10 percentage points depending on the poverty definition used in the analysis. Mora Rivera [2005] studies the impact of migration and remittances on the distribution and sources of income in rural communities in Mexico. His main finding is that rural households invest part of their income generated from remittances in productive activities and in turn remittances decrease household's inequality. Acosta et al [2007b] use a large cross-country panel dataset for Latin American and Caribbean countries and find that remittances reduce poverty. Adams and Page [2005] examine the impact of international migration and remittances on poverty in 71 developing countries (including the countries analyzed in this paper: El Salvador, Mexico, and Turkey). They find that remittances reduce the level, depth, and severity of poverty in the developing world. In particular, their empirical results indicate that a 10 percent increase in per capita official international remittances will lead to a 3.5 percent decline in the share of people living in poverty. Orrenius et al [2009] study the impact of remittances on regional economic development in Mexico. They analyze such impact on different fronts: wages, employment, unemployment rates, wage inequality, and school enrollment rates. Using a state-level data from Mexico during 2003-2007, they find that remittances shift the wage distribution to the right by reducing the fraction of workers earning the minimum wage or less. This can be interpreted as reduction in inequality in Mexico.

Recent studies indicate that remittances also play a key role in the financial sector development. For example, Woodruff and Zenteno [2006] analyze whether migration networks lower capital costs and alleviate capital constraints. Using a survey of more than 6,000 selfemployed workers and small firm owners located in 44 urban areas of Mexico, they find that migration is associated with higher investment levels, especially in automobiles, tools and inventories. Furthermore, their empirical results suggest that remittances alleviate capital constraints fostering economic development. Demirgüç-Kunt et al [2007] investigate the impact 
of remittances on financial depth and breadth by using county-level data for Mexico on the percentage of households that receives remittances and the number of branches, the number of deposits, and the volume of deposits and credit across counties. They find that remittances have a positive impact on financial depth and breadth, in particular when they concentrate on deposit services and branch penetration. Giuliano and Ruiz-Arranz [2009] study how local financial sector development influences a country's capacity to take advantage of remittances. Using a dataset that contains 100 developing countries, they find that remittances induce economic growth in countries with less developed financial systems by providing an alternative way to finance investment and overcoming liquidity constraints.

\section{Remittances: self-interest or altruism?}

From a theoretical perspective, there are several potential forces and motives behind migrants deciding whether to remit money back home to relatives. Rapoport and Docquier [2006] provide an excellent summary of both the microeconomic and macroeconomic theoretical frameworks behind remittances. According to Rapoport and Docquier, at the micro level-that is at the migrant or household level-there are six main motives to remit money home. These micro motives behind remittances combine (1) an altruistic component, (2) an exchange component, (3) an inheritance component, (4) a strategic motive component, (5) an insurance component, and (6) an investment component. The first four are pure individual motives while the last two are familial and household arrangement motives. Most of the previous microeconomics literature on remittances has focused only on the altruism component. However, Rapaport and Docquier argue that all of the above motives are key drivers for remittances, and more importantly, they indicate that it is extremely difficult to empirically discriminate between these different motives.

Rapaport and Docquier propose different theoretical microeconomic models to analyze the dynamics of the different motives discussed above. More specifically, they analyze how remittances respond-under each of the six motives-to different explanatory variables such as migrant's income, migrant's education, time since arrival in source country, distance from family, number of migrants and heirs in each household, recipient's income, adverse shocks in recipient's income, and recipient's assets. ${ }^{6}$ For the purpose of my analysis in this paper, two motives are of particular importance: (1) the altruism motive and (2) the investment motive as an indicator for the self-interest motive.

\footnotetext{
${ }^{6}$ See Table 2 , in page 1163 , for more details.
} 
According to Rapaport and Docquier, remittances are positively correlated-under both motives-to migrant's income; therefore, we should see a positive correlation between the output (income) for the host or source country and remittances. When looking at the self-interest or investment motive and its relationship with recipient's income, remittances respond differently under the altruism motive than under the self-interest (investment) motive in relationship with the recipients' income. Under the altruism motive, remittances are negatively correlated or counter-cyclical to recipient's income, therefore, if output (income) in the home country is growing, we should observe a decline in remittances. Under the self-interest (investment) motive, remittances are positively correlated to recipient's income or pro-cyclical, that is output (income) in the home country.

The altruism motive and the investment motive work against each other and perhaps can offset each other to some extent. The analysis I perform in this paper concentrates on the net effect between remittances and output in both home and host countries. Therefore, I am not able to discriminate between these two opposing forces. More importantly, in the event that both forces exactly offset each other, then remittances will be asynchronous to output in the home country. ${ }^{7}$

\section{Previous studies on business cycles and remittances}

Remittances arguably are considered to have a tendency to be pro-cyclical with the source or host country (i.e. the United States) and to be counter-cyclical with the receiving or home country (i.e. Mexico). There are just a few studies analyzing remittances and business cycles of both receiving and source countries (see Table 2 for a summary of the existing literature and main empirical results). Ratha [2003] argues that remittances are more stable than private capital flows and may even respond to changes in economic cycles in the recipient country. Sayan [2006] is the first to address the question of whether remittances are pro- or counter-cyclical with output employing econometric techniques. Sayan studies remittances and business cycles for 12 developing countries using annual data for the period of 1976-2003. Using a polynomial fitting model, Sayan obtains the trend for the different time series and then removes such trend to get the cyclical component for each series. Sayan then computes contemporaneous cross-correlation and asynchronous correlation coefficients using only the cyclical components and finds that

\footnotetext{
${ }^{7}$ I find that remittances to El Salvador are weakly counter-cyclical with El Salvadorian economy. See section 7 for more details.
} 
remittance receipts by the group of countries in the sample move counter-cyclically with the aggregate output for the whole group over the sample period (1976-2003). Moreover, Sayan finds that at the individual country level, remittance flows are counter-cyclical for some countries whereas for others remittances are pro-cyclical or even acyclical. Therefore, the empirical results, offered by Sayan, are to some extent inconclusive regarding whether remittances flows move counter- or pro-cyclical with the recipient country output.

Apaa-Okello and Anguyo [2006] investigate the counter-cyclical versus the pro-cyclical arguments of worker remittances to the movements of output for Uganda. Using annual data over the period 1992-2005, the authors employ two methodologies to remove the time varying trend from each series: (1) the Hodrick-Prescott [1997] filter (hereafter referred to as HP) and (2) Christiano-Fitzgerald [2003] filter (hereafter referred to as CF). The latter is an asymmetric band-pass filter and the authors argue that this filter is advantageous over the other band-pass filters such as the Baxter-King [1997] filter (hereafter referred to as BK), because the symmetric filter requires the same number of lead and lag terms for every weighted moving average resulting in omitting observations both at the beginning and at the end of the sample. On the other hand, an asymmetric filter, like the CF filter, does not require this and therefore can be estimated to the extreme end points of the original sample. Further, the weights on the leads and the lags are allowed to differ depending on the data. Correlation analysis results suggest that remittance receipts to Uganda are pro-cyclical to the business cycle of that country.

India is the top remittance receiver in the world, with roughly $\$ 28$ billion in remittance income in 2007. Gupta [2005] analyzes the macroeconomic factors that explain the dynamics of remittances to India. Gupta uses different economic indicators as proxy for host or source country business such as United States employment, LIBOR, and oil prices while economic conditions in India are measured by industrial production and the return on the Bombay Stock Exchange. Simple correlation analysis point to remittances being positive correlated with United States employment. In addition to using both the HP filter and first-differences, Gupta enhances the analysis by incorporating some econometric modeling and finds that remittances to India are positively correlated to economic conditions in the host or source country and negatively but weakly correlated with economic conditions in India.

Sayan and Tekin-Koru [2007] document whether remittances sent to Turkey by Turkish workers living in Germany are counter- or pro-cyclical with Turkish and German national 
outputs. Further, they expand their analysis by estimating whether remittance flows help alleviate poverty or not. Their methodology framework is based on decomposing remittance and output series into permanent and cyclical components. They use a polynomial fitting model and the HP filter to extract the stationary cyclical component for each time series. Then, Sayan and Tekin-Koru compute cross-correlations between the cyclical components of remittances and Turkish and German output series. Their empirical results indicate that co-movements of cyclical components of the real remittance flows from Germany and the real GDP in Turkey are pro-cyclical. Furthermore, they find that remittance flows from Germany to Turkey are procyclical with the German economy. In turn, these results suggest that remittance flows from Germany are likely to amplify fluctuations observed over business cycles in Turkey, contradicting economic theory predictions of remittances being counter-cyclical with the home country business cycle.

Lueth and Ruiz-Arranz [2007] explore to what extent workers' remittances have helped cushion Sri Lanka against economic shocks. They estimate a vector-error-correction (VEC) model for Sri Lanka to determine the response of remittance receipts to shocks in macroeconomic variables. They employ quarterly data for the period 1996-2004. Some of the macroeconomic variables in their analysis include real GDP in the receiving country, the exchange rate, and the relative return (relative interest rate). Given the unavailability of the GDP for the host country, the authors use world oil price as a proxy given that the GDP in the host country is heavily dependent on oil exports. Their results suggest that remittances are procyclical with the home country economic conditions. Similar to the results found by Sayan and Tekin-Koru [2007] for Turkey, Lueth and Ruiz-Arranz also find that remittances amplify the business cycles fluctuations in the case of Sri Lanka.

Vargas-Silva [2009] documents the business cycle properties of workers' remittance flows to Mexico. Vargas-Silva argues that it is not clear whether remittances should be pro- or countercyclical given the different forces that impact remittance flows. On one hand, there might be altruist forces and in that case remittances should react counter-cyclically to smooth consumption and contribute to the stability of the recipient economy [Agarwal and Horowitz 2002]. On the other hand, there might be self-interest motives for remitting, such as investment and interest in inheriting from the household's assets, resulting in remittances being pro-cyclical with the recipient country [Woodruff and Zentento 2001; de la Briere et al 2002]. Therefore, the 
relationship between remittances and recipient country business cycle is not straightforward. Vargas-Silva analysis is threefold. First, he extracts the stationary cyclical component of the macroeconomic time series (remittances and output) by using the BK filter. Secondly, he computes cross-correlations between the cyclical components (both contemporaneous and shifting the series backward and forward up to three quarters) to assess whether remittances are pro- or counter-cyclical with output. Finally, the author develops a vector-autoregressive (VAR) model and uses it to construct impulse response functions to show the predictable response of each variable after a shock in another variable. The dataset spans from 1981 to 2006 and contains quarterly data. Empirical results indicate that remittances are associated negatively and significantly with Mexico's output while remittances are weakly positively correlated with United States output. Vargas-Silva argues that perhaps looking at the fluctuations of the sectors where Mexican immigrants predominately work, such as construction; one could find stronger linkages between these United States sectors and remittance fluctuations.

Vargas-Silva and Huang [2006] study the determinants of worker remittances for a number of Latin American countries including Brazil, Colombia, Dominican Republic, El Salvador and Mexico. Using quarterly data for the period 1981-2003, they employ a VEC model to test if remittances are affected by the macroeconomic conditions in the United States (sending country) or in the different receiving countries in Latin America. Empirical results suggest that remittances respond more to changes in the macroeconomic conditions in the host country, namely the United States, than to changes in the macroeconomic conditions in the home country. Using impulse response functions, they find that remittances respond positively to shocks in the monetary base of the United States, suggesting that remittances sent to Latin American countries are positively correlated to the United States business cycle. In the case of Mexico, the authors find only weak correlation between remittances and the Mexican macroeconomic indicators. For the rest of the Latin American countries, local macroeconomic conditions do not affect the amount of remittances sent home by workers in the United States.

Bora Durdu and Sayan [2008] analyze the implications of remittance fluctuations for various macroeconomic variables and Sudden Stops. The authors develop a small-open economy twosector model with financial frictions which is calibrated to Mexican and Turkish economies. Using quarterly data from the 1980s, the authors find that remittance flows to Mexico from the United States are counter-cyclical to the business cycle in Mexico, whereas Turkish remittances 
are pro-cyclical and followed the business cycle in Turkey with a one-quarter lag. In essence, their empirical results indicate that remittances dampen the business cycles in Mexico whereas they amplify the cycles in Turkey.

Magnusson [2009] takes a more regional approach when investigating how remittance flows respond to business cycles conditions between the United States and Latin America. Magnusson argues that the lack of empirical evidence linking macroeconomic variables in the United States to remittances sent to Latin America is because Hispanic immigrants are not uniformly distributed across the United States (in fact, concentrated in specific areas) and thus, it is hard to find strong linkages between overall macroeconomic variables, such as GDP and remittance flows, to Latin American economies. Instead, Magnusson proposes to use regional economic indicators, such as state-level business cycles and state-level employment in construction and leisure sectors, as a way to gauge business cycle properties in the sectors where most Hispanic migrants work. Using quarterly data from the mid-1990s for Mexico and El Salvador, Magnusson obtains the cyclical portion of the different time series employing the HP filter and first-differences. Results from simple correlation analysis indicate that there exists a strong positive correlation between state-level indicators and remittances sent to Mexico and El Salvador. As a robustness check, Magnusson proposes a distributed lag model to model the impact that regional business cycles have on remittance flows. Again, empirical results from the econometric model indicate that remittances to Mexico and to El Salvador are significantly impacted by business conditions in the construction and leisure sectors at the state level. Overall, Magnusson finds a strong positive impact on remittances to Mexico and to El Salvador from regional business cycle indicators in the United States.

Giuliano and Ruiz-Arranz [2009] study the link between remittances and growth; particularly they concentrate on how local financial sector development influences a country's capacity to take advantage of remittances (paper discussed into more detail in Section 2). Furthermore, Giuliano and Ruiz-Arranz analyze the cyclical components of remittances and output series employing the HP filter. They conclude that for roughly two-thirds of the countries in the sample remittances are pro-cyclical with local business cycles while for the remaining countries remittances are counter-cyclical with the domestic economy.

Roache and Gradzka [2007] assess the strength and significance of linkages between remittance flows to Latin America and the United States business cycle. Using quarterly data 
from 1990 to 2007, Roache and Gradzka employ different methods including correlation and cointegration analysis, a distributed lag estimation model, as well as a dynamic factor model. Their empirical results suggest that remittance flows are relatively impacted by fluctuations in the United States business cycle, underlying their role as a stable source of external financing in good times and bad in the receiving country. In particular, their correlation and cointegration analysis indicates that for only a few countries there is evidence of a stable long-run relationship between remittances and output fluctuations in the United States. The authors clearly recognize that these results might be influenced by the small sample size. With respect to their distributed lag estimation model, empirical results indicate that for only a handful number of countries there seems to be a statistically significant impact of the United States business cycle into the remittance flows to the Latin American economies.

Roache and Gradzka are the first, to my knowledge, to utilize a dynamic factor model to study remittances and business cycle fluctuations. They use a standard dynamic factor statespace model where the set of observed variables-including remittances and the United States business cycle-are assumed to be linear functions of a set of unobserved "state variables" or common factors. Their results indicate weak, or nonexistent, linkages between remittances and the United States indicators over the sample period. Following the footsteps of Clark [1987], the authors assumed that the disturbance terms between the state and measurement equations to be uncorrelated. Clark found that if the orthogonality is assumed, most of the variation in the United States output can be attributed to the cyclical component with little variation attributable to the permanent or trend component. Beveridge and Nelson [1981] (hereafter referred to as $\mathrm{BN}$ ), on the other hand, employed an ARIMA methodology to decompose output in the United States into stochastic permanent and cyclical components and found that most of the variation in output can be attributed to the permanent or trend component. Morley, Nelson and Zivot [2003], in a recent paper, show that once the orthogonality assumption is relaxed, Clark's unobservedcomponents model and the transfer ARIMA model by BN provide exactly the same results. Therefore, it might not be surprising that Roache and Gradzka find weak correlation in the cyclical components of United States output and Latin America remittances given their implicit assumptions behind their econometric model. One of the main contributions of this paper is precisely in relaxing the orthogonality assumption. In the following section, I present the model that I use to extract the permanent and cyclical components in the remittance and output series. 


\section{The econometric model}

The traditional unobserved components [hereafter UC] or "state space" model to decompose gross domestic product — or any other macroeconomic time series such as industrial production or remittances-into an independent nonstationary trend and stationary cyclical components is as follows:

$$
\begin{array}{ll}
y_{t}=\tau_{t}+c_{t} \\
\tau_{t}=\tau_{t-1}+g_{t-1}+\eta_{t} ; & \eta_{t} \sim \text { i.i.d. } N\left(0, \sigma_{\eta}^{2}\right) \\
g_{t}=g_{t-1}+v_{t} ; & v_{t} \sim \text { i.i.d. N }\left(0, \sigma_{v}^{2}\right) \\
\phi(L) c_{t}=\varepsilon_{t} ; & \varepsilon_{t} \sim \text { i.i.d. } N\left(0, \sigma_{\varepsilon}^{2}\right)
\end{array}
$$

where $\left\{y_{t}\right\}$ is the log of observed series, $\left\{\tau_{t}\right\}$ is the unobserved stochastic trend component, and $\left\{c_{t}\right\}$ is the unobserved stochastic cyclical component. The trend component is assumed to be a random walk with a drift while the transitory component is stationary. Clark [1987] proposed the above model to analyze output and industrial production in the United States. Further, Clark proposed $\eta_{t}, v_{t}$, and $\varepsilon_{t}$ to be independent "white noise" processes. In essence, Clark's assumption implies that innovations in the trend and cycle components are independent. This assumption is clearly not realistic and even Clark recognized this. However, Clark argued that this assumption was necessary to ensure that the UC model could be identified.

The above UC model can be estimated by using state space techniques to find the likelihood function of the sample $y_{t}$, given $\sigma_{\eta}^{2}, \sigma_{v}^{2}$ and $\sigma_{\varepsilon}^{2}$, and the AR coefficients in $\phi(L)$. The optimal lag structure can be identified by estimating different lag specifications for the autoregressive polynomial, $\phi(L)$, and the specification with the optimal selection criterion (such as Akaike information criterion or Schwartz information criteria) is then selected. ${ }^{8}$ If the error

\footnotetext{
${ }^{8}$ As an example, it is widely accepted in the profession that for the United States the cyclical component follows an AR(2) [Clark 1987; Hamilton 1989; Morley, Nelson and Zivot 2003] and therefore, the state-space model is as follows:

State or Transition Equation:

$$
\left[\begin{array}{c}
{ }^{c}{ }_{t} \\
{ }^{c}{ }_{t-1} \\
{ }^{t}{ }_{t} \\
g_{t}
\end{array}\right]=\left[\begin{array}{cccc}
\varphi_{1} & \varphi_{2} & 0 & 0 \\
1 & 0 & 0 & 0 \\
0 & 0 & 1 & 1 \\
0 & 0 & 0 & 1
\end{array}\right] *\left[\begin{array}{c}
{ }^{c} t-1 \\
{ }^{c} t-2 \\
\tau \\
{ }_{t-1} \\
g_{t-1}
\end{array}\right]+\left[\begin{array}{c}
{ }^{t} \\
0 \\
\eta_{t} \\
{ }_{t}
\end{array}\right]
$$
}


terms are assumed to be normally distributed, then parameters of the UC model can be estimated employing maximum likelihood techniques. For instance, parameter estimates in the above system can be obtained by starting with an initial guess for the state vector and its covariance matrix. Given the initial estimated parameters, the Kalman filter recursively generates the prediction and updating equations. Ultimately, the Kalman filter generates both unobserved components $\left\{\tau_{t}\right\}$ and $\left\{c_{t}\right\}$.

Clark found that at least half of the quarterly innovation in the United States output can be attributed to a stationary cyclical component that persists over periods of time as long as five years. This finding was inconsistent, at least to the evidence at the time, with the hypothesis that most of the apparent variation in United States economic activity can be attributed to a nonstationary trend component. Clark argued, in other words, employing the UC model assuming independent innovations, a substantial fraction of the short-run variation in output is due to a persistent business cycle, with less variation allocated to a stochastic trend that evolves fairly smoothly over time.

Prior to Clark's UC model, Beveridge and Nelson [1981] proposed a general procedure for the decomposition of a nonstationary time series into a permanent component and a transitory component allowing both to be stochastic. ${ }^{9}$ Furthermore, the permanent component is shown to be a random walk with drift and the transitory or cyclical component is a stationary process with mean zero. The $\mathrm{BN}$ decomposition is as follows:

$$
\phi(L)\left[\Delta y_{t}-\mu\right]=\theta(L) \varepsilon_{t},
$$

where the permanent component is defined by:

$$
\Delta \tau_{t}=\mu+\psi(1) \varepsilon_{t} ; \quad \text { where } \psi(L)=\theta(L) \phi(L)^{-1},
$$

and the transitory component is defined as follows:

$$
c_{t}=\tilde{\psi}(L) \varepsilon_{t} ; \quad \text { where } \tilde{\psi}(L)=-\sum_{k=j+1}^{\infty} \psi_{k}
$$

Measurement Equation: $\quad y_{t}=\left\lfloor\begin{array}{lll}0 & 1 & 0\end{array}\right]\left[\begin{array}{c}c_{t} \\ c_{t-1} \\ \tau_{t} \\ g_{t}\end{array}\right]$

${ }^{9}$ The time series needs to be non-stationary in levels but stationary in first-differences. In order to ensure this condition is satisfied, I conduct unit-root tests for both levels and first-difference and show that the time-series in this analysis comply with this requirement for the $\mathrm{BN}$ decomposition. 
Clearly, the permanent component is invariably a random walk with the same rate of drift as the original data and an innovation which is proportional to that of the original data. The difference between the permanent component and the actual value of the series is then the momentum contained in the series at a point in time and is a natural measure of its transitory or cyclical component. The transitory component is a stationary process with zero mean. BN find that their methodology provides expansions and contractions in the estimated United States business cycles that are roughly equivalent in duration and timing to those identified by the National Bureau of Economic Research, which is the official dating institution regarding business cycles in the United States. Furthermore, their findings suggest that the stochastic trend accounts for most of the variation in output, contrary to Clark's findings where the cyclical component is dominant.

Morley, Nelson and Zivot [2003] in an attempt to reconcile the difference between both methodologies, demonstrated that Clark's innovation independence assumption is not necessary for the model to be estimated. Furthermore, they show that once the orthogonality assumption is relaxed, both Clark's UC model and BN transfer ARIMA model provide the same decomposition results. Morley, Nelson and Zivot also document that the innovations to trend are strongly negatively corrected $(\rho=-0.9)$ with innovations to the cycle.

\section{Data}

Mexico Analysis: The data used here for the Mexico analysis come from different sources in the United States and Mexico. There are three main time series employed here: (1) workers' remittances received by Mexico from the United States, (2) Mexico's GDP, and (3) the GDP for the United States. The first series comes from the Central Bank in Mexico (Banco de México) and is published at a quarterly frequency in dollars for the period 1960:Q1 through 2008:Q4. I seasonally adjust remittances employing the Bureau of Labor Statistics (BLS) X12 methodology and then I deflate the series using the United States consumer price index for all urban consumers produced by the BLS. ${ }^{10}$ The second series employed in this paper is Mexico's gross domestic product (GDP) which is produced by Mexico's INEGI and is available on a quarterly

\footnotetext{
${ }^{10}$ The CPI index is published at a monthly frequency so I take the average of the three months corresponding to each quarter.
} 
basis in real pesos and seasonally adjusted for the period 1980:Q1 through 2008:Q4. ${ }^{11}$ The last series is GDP for the United States and this series comes from the Bureau of Economic Analysis and the data are seasonally-adjusted, deflated and available on a quarterly basis for the period 1960:Q1 through 2008:Q4. ${ }^{12}$

El Salvador Analysis: The data used here for the El Salvadorian analysis come from different sources in the United States and El Salvador. Similar to the analysis for Mexico, three time series are employed: (1) workers' remittances received by El Salvador from the United States, (2) El Salvador's GDP, and (3) the GDP for the United States. The first series comes from the Central Bank in El Salvador (Banco Central de la Reserva) and is published at a monthly frequency in dollars for the period January 1991 through December 2008. I convert the series into a quarterly frequency by summing the three months corresponding to the quarterly counterpart. I then seasonally adjust remittances to El Salvador employing the Bureau of Labor Statistics (BLS) X12 methodology and I deflate the series using the United States consumer price index for all urban consumers produced by the BLS. ${ }^{13}$ The second series employed in this paper is El Salvador's gross domestic product (GDP) which is produced by El Salvador's Central Bank and is available on a quarterly basis in real dollars for the period 1990:Q1 through 2008:Q4. Similar to the remittances series, I employ the BLS X12 procedure to seasonally adjust the data. The last series is GDP for the United States and this series is the same as the one used in the Mexico analysis. ${ }^{12}$

Turkey Analysis: For Turkey, I employ remittances from Germany to Turkey and output series for both Turkey and Germany. The remittances to Turkey series come from Germany's Central Bank and are available from the first quarter in $1971 .{ }^{14}$ For the period 1971:Q1 to 1987:Q4 this data series is in Dutch Marks while after 1988:Q1 is in Euros. I converted both series into dollars utilizing the nominal exchange rate. I deflate the dollar-denominated remittance series using the United States CPI and then I seasonally adjusted the series using BLS

\footnotetext{
${ }^{11}$ INEGI stands for Instituto Nacional de Estadística, Geografía e Informática and performs statistical work comparable to that done in the United States by the Census Bureau, Bureau of Labor and Statistics, and Bureau of Economic Analysis. Unfortunately, data for Mexican GDP only starts in 1980:Q1.

${ }^{12}$ See Figure 1 for charts of the data.

${ }^{13}$ See footnote 10.

${ }^{14}$ For the case of Germany and Turkey, I use remittances send from Germany to Turkey. I obtained these data from the Central Bank of Germany. For the case of Mexico and El Salvador, I use remittance data provided by central banks in those two countries and I further assume that all remittances received come from the United States. Given that practically all migrants from Mexico and El Salvador go to the United States, such assumption should not alter my empirical findings.
} 
X12 procedure. ${ }^{15}$ Turkey's output series comes from the Turkish Statistical Institute and is available from 1987:Q1 in real Turkish Liras and is seasonally adjusted by such statistical agency. Germany's GDP begins in 1991:Q1 and is in real seasonally adjusted Euros provided by the Organization for Economic Cooperation and Development (OECD). ${ }^{12}$

\section{Empirical results}

Given that Morley, Nelson and Zivot [2003] demonstrated that the decomposition of a time series into permanent trend and cyclical components under the UC model is equivalent to the BN model and that the $\mathrm{BN}$ methodology is far easier to implement from an econometric point of view, I conduct all my empirical analysis employing the BN methodology. As a comparison between the methodology employed in this paper and the methodologies employed in the previous studies, I also estimate the cyclical component out of the three time series utilizing the HP filter, BK filter, CF filter, and a polynomial fitting model. Furthermore, I demonstrate in the following paragraphs that the more modern and sophisticated econometric technique employed here, namely the $\mathrm{BN}$, outperforms the rest of the methods previously utilized in the literature.

Before estimating the permanent and transitory components of each time series employing the BN decomposition, I need to check if the series are stationary or not. I use the ElliotRothenberg-Stock [1996] unit root test to accomplish this using the natural log of each of the series. ${ }^{16}$ Results of the unit root tests using log-level data are provided in the top portion of Table 3 where I show that I fail to reject the null hypothesis that there exists a unit root for each of the eight time series. ${ }^{17}$ This implies that each time series then follows a unit root process and therefore they are not stationary time series, in log-levels. ${ }^{18}$ This is the desired condition, that the series are non-stationary in log-levels, so that the BN decomposition can be implemented.

I also conducted unit root tests for the log first-difference of each time series and I reject the null hypothesis at the 99\% level for all time series except El Salvadorian and Germany's output series. For El Salvador and Germany's GDP series, the null hypothesis is barely rejected at the $10 \%$ level and rejected at the 5\% level, respectively. This, in turn, implies that by just

\footnotetext{
${ }^{15}$ See footnote 10.

${ }^{16}$ In essence, I perform the Dickey-Fuller Test with GLS Detrending (DF-GLS) as proposed by Eliott, Rothenberg, and Stock [1996] with a constant and a linear time trend.

${ }^{17}$ The eight series include remittances to Mexico, to El Salvador, and to Turkey; and GDP for Mexico, the United States, El Salvador, Germany and Turkey.

${ }^{18}$ As a robustness check, I also performed the Augmented Dickey-Fuller (ADF) unit root test for all the eight time series and obtain the same results as with the DF-GLS unit root tests shown in Table 3. The ADF results are available upon request.
} 
differencing once, the eight time series on hand become stationary. Results for the log firstdifference unit root tests are also provided in Table 3.

Furthermore, before employing the $\mathrm{BN}$ decomposition, I need to find the optimal lag structure for both polynomials: $\varphi(\mathrm{L})$ and $\theta(\mathrm{L})$. I run all possible combinations of $\operatorname{ARIMA}(p, 1, q)$ models allowing $p$ and $q$ to vary between zero and twelve. ${ }^{19}$ I selected the model with the lowest Schwartz Information Criterion for each time series. ${ }^{20}$ The optimal lag structure for each of the time series is as follows: remittances to Mexico $\operatorname{ARIMA}(2,1,0)$; United States' output ARIMA(1,1,0); Mexico's GDP ARIMA(0,1,2); remittances to El Salvador ARIMA(0,1,0); El Salvador GDP ARIMA(0,1,2); remittances to Turkey ARIMA (0,1,1); Germany's output $\operatorname{ARIMA}(0,1,0)$; and Turkey's GDP ARIMA $(1,1,0)$. Table 4 reports the optimal-lag regressions output for each time series.

Once I identify the optimal lag polynomials for both the auto-regressive and moving-average terms, I can now obtain the stationary cyclical component of each series employing the BN decomposition. In essence, the stationary cyclical components are obtained by computing $\psi(L)=\theta(L) \phi(L)^{-1}$ and then $\tilde{\psi}(L)=-\sum_{k=j+1}^{\infty} \psi_{k} \cdot{ }^{21}$ Figure 2 illustrates the BN cyclical components for each series under their optimal lag structure.

Again, for comparison purposes with previous studies, I also estimate the permanent and cyclical components of each series using various band-pass filters and a polynomial fitting model. I use the HP filter $(\lambda=1600)$ and the cyclical components are provided in Figure 3. Further, the cyclical components under the BK filter $(k=14)$ are shown in Figure $4 .{ }^{22}$ Figure 5 shows the cyclical portion of the eight time series employing the CF asymmetric band-pass filter. $^{23}$ Last, I also estimated the cyclical component of the time series via a polynomial fitting model. In order to obtain the optimal power under the polynomial fitting model, I estimated all possible model specifications and chose the one with the lowest Schwartz Information Criteria.

\footnotetext{
${ }^{19}$ I ran 169 model specifications for each of the eight time series. Results for these models are not presented here, but are available upon request.

${ }^{20}$ I selected the model with lowest Schwartz Information Criterion given that this criterion is more restrictive than the Akaike Information Criterion.

${ }^{21}$ I employ the James C. Morley GAUSS programs to obtain the BN cycle.

${ }^{22}$ I use the fixed-length symmetric Baxter-King frequency filter with 14 lags as the maximum lag structure. For the cycle periods, I assume 6 to be the low bound and 32 the high bound.

${ }^{23}$ I use the fixed-length symmetric Christiano-Fitzgerald frequency filter with 12 lags as the maximum lag structure. For the cycle periods, I assume 6 to be the low bound and 32 the high bound.
} 
For the remittances to Mexico and remittances to El Salvador, I set the maximum polynomial term to be to the tenth power while for Mexico's GDP and El Salvador output series the maximum power employed was seven. For the United States GDP series the maximum power employed was eight. Regarding the analysis for Turkey, the optimal maximum polynomial power for remittances to Turkey, for Turkey GDP's and for Germany's GDP was the fifth power, sixth power and fourth power, respectively. The polynomial fitting model is an estimate of the trend component and therefore the residuals are the cyclical portion of the series. Figure 6 illustrates the cyclical components estimated under this methodology.

Once the stationary cyclical components are obtained under all the different methodologies mentioned above, I compute cross-correlation coefficients to identify whether remittances are pro- or counter-cyclical with output fluctuations. I calculate both contemporaneous crosscorrelation coefficients as well as asynchronous cross-correlation coefficients between the different remittance and output series. I allow the output series to shift backward and forward by 16 periods (quarters) when computing the asynchronous cross-correlation coefficients. The correlation coefficient is calculated as follows:

$$
\hat{\rho}_{x y}(k)=\frac{\sum_{t=1}^{n-k}\left(x_{t}-\bar{x}\right)\left(y_{t+k}-\bar{y}\right)}{\hat{\sigma}_{x} \hat{\sigma}_{y}}, \text { for } k=0, \pm 1, \pm 2, \ldots, \pm 16 .
$$

Remittances are said to be pro-cyclical (counter-cyclical) with real output if the contemporaneous cross-correlation (cross-correlation at time $t=0$ ) between the two series is positive (negative) and statistically significant. Similar intuition holds for the asynchronous cross-correlation coefficient with the additional insight that asynchronous cross-correlation coefficients will allow us to examine possible phase-shift significant impacts of output on remittances.

Empirical results for Mexico ${ }^{24}$

Empirical results for the cross-correlation analysis for the Mexican case, under all methodologies, are reported in Figure $8 .{ }^{25}$ Given the negative and statistically significant

\footnotetext{
${ }^{24}$ As a robustness check, I also computed the BN decomposition for each series assuming an $\operatorname{ARIMA}(2,1,2)$. For brevity reasons, I do not report both the regression and cross-correlation results. However, these are available upon request. In summary, the empirical results, under this model specification, indicate that there is no correlation between Mexico's output and remittances and that there is a negative correlation between United States GDP and remittances. Given that the BN lag structure employed here is not the optimal lag structure, it is not surprising that results are not aligned to those obtained under the optimal lag structure analysis. Therefore, it can be concluded that the BN methodology empirical results are sensitive to lag specification.
} 
correlation coefficient, with $k=0$ and $k=-1$, between the cyclical components of remittances and the United States output, we can conclude that remittances are counter-cyclical with output in the United States. This result contradicts the anticipated positive relationship between remittances and source country.

As reported in Figure 8, there is a negative and statistically significant cross-correlation coefficient with $k=2$ between remittances and Mexico's output, we can interpret remittances being counter-cyclical with the Mexican economy. As described in Section 3, Mexican immigrants in the United States face two opposing forces (altruism vs. "self-interest" or investment) when deciding whether to remit money back home to family and relatives. Given that the cross-correlation coefficient is negative and significant at the 5 percent level, it can be concluded that the altruism motive dominates over the self-interest motive.

Given that most of the previous studies rely on either the HP or the BK band-pass filters to decompose remittances and output series when analyzing the pro- or counter-cyclicality of remittances, I also conducted such decompositions to compare results under these alternative methodologies to the UC state-space model (via BN decomposition). As stated above, such analysis typically provide inconclusive evidence or in some cases evidence that does not correspond to economic theory; for instance, remittances are counter-cyclical with host country and pro-cyclical with home country (remittances magnify fluctuations of business cycles at home) [see Table 2]. Under such band-pass filters, there is a strong and positive correlation between remittances to Mexico and United States economic fluctuations, as reported in Figure 8. These results are aligned with existing research that indicates that remittances are positively correlated to source country output fluctuations. However, as Cogley and Nason [1995] argue, the HP filter can generate business cycle dynamics even if none are present in the original data. Further, Cogley and Nason demonstrate cross-correlation functions for HP filtered random walks exhibit positive and statistically significant correlation clustered at $k=0$ and then such strong and positive correlation vanishes as $k$ either increases or decreases. In fact, the cross-correlation functions exhibited in Cogley and Nason's paper are identical to the ones I obtained in my analysis. Cogley and Nason argue that HP filtered data can exhibit periodicity and co-movement over business cycle horizons even if none are present in the input series. Therefore, business

\footnotetext{
${ }^{25}$ The different horizontal bands in each graph represent the $10 \%, 5 \%$, and $1 \%$ significance levels, reading from inside the $\mathrm{x}$-axis out. On the $\mathrm{x}$-axis, I report $k= \pm 16$ lags. On the $\mathrm{y}$-axis, I report the correlation coefficient between the remittance and output series.
} 
cycles under the HP filtered data does not necessarily imply that there are business cycle in the original data. $^{26}$

In attempt to make my empirical analysis fully comparable to the existing literature, I also estimate the cyclical portion of the time series under the CF filter and a polynomial fitting model. Again, Figure 8 reports the correlation analysis results under both methodologies. In essence, the empirical results under the $\mathrm{CF}$ filter and a polynomial fitting model are aligned with the previous studies and are practically equivalent to the results obtained under the HP and BK bandpass filters. In summary, under such filters, empirical results are inconclusive regarding the relationship between remittances and Mexico's output while remittances are pro-cyclical with United States business cycle.

The empirical results provided here, in particular under the $\mathrm{BN}$ methodology, indicate that remittances respond to output conditions in both the United States and Mexico in a quick fashion, the cross-correlation coefficients that are statistically significant fall under 1- and 2quarter lag or lead. More importantly, I provide empirical evidence in this paper that once more advanced and current econometric techniques are employed to decipher the cyclical components of output series for both Mexico and the United States and remittances, remittances respond negatively to business conditions both in the United States and in Mexico. Contrary to previous studies, the empirical results presented here are more aligned with economic theory suggesting that remittances help buffer economic shocks at home; however, my empirical results with respect to source country are not aligned to the anticipated prediction by economic theory that is that remittances should be positively related to the business cycle in the source country. ${ }^{27}$

\section{Empirical Results for El Salvador}

Figure 9 reports the empirical results for the cross-correlation analysis for El Salvador, under all methodologies. ${ }^{28}$ The BN cross-correlation functions indicate that remittances are procyclical, as anticipated, with the United States business cycle given that both the

\footnotetext{
26 See note 2, Murray makes a similar case for the BK band-pass filter.

27 This is the opposite result, perhaps by breaking the remittance time series into two potential structural breaks, the results will change. See later in this section for the structural break analysis. Another explanation might rely on the use of aggregate output. Vargas-Silva [2009] and Magnusson [2009] argue that output for the United States is not necessarily representative of income of Mexican migrants. They propose to use alternative time series such as data from the specific sectors such as construction and certain services industries. Their argument is that most Mexican migrants work in such sectors and therefore income fluctuations will be better captured by concentrating in these sectors.

${ }^{28}$ See footnote 25 .
} 
contemporaneous cross-correlation coefficient and the one with $k=-1$ are positive and significant at the $10 \%$ and $5 \%$, respectively. With respect to El Salvadorian economy, remittances are [weakly] counter-cyclical given that the cross-correlation coefficients with $k=-1$ and $k=3$ are negative but weakly significant, the p-values are 0.13 and 0.10 . There are two potential explanations for such weak counter-cyclicality. First, perhaps these weak results under the BN are due to short sample span in the dataset. However, none of the other filters employed in the analysis find these types of empirical results as the ones provided by the BN methodology. Secondly, as described in Section 3, migrants in the United States face, among many others, two main opposing forces when deciding whether to remit money back to El Salvador. The results I obtain here for El Salvador suggest that to some extent both motives offset each other; however, it appears that the altruism weakly dominates over the self-interest or investment motive given that remittances are weakly counter-cyclical with output fluctuations in El Salvador.

Similar to the Mexican analysis, I employ a battery of band-pass filters and a polynomial fitting model to compare and contrast my BN empirical results. The first band-pass filter that I use is the HP filter and results under the HP filter indicate that remittances are pro-cyclical with United States business cycle while there is no statistically significant evidence that remittances are either pro- or counter-cyclical with business fluctuations in El Salvador. This implies that remittances are asynchronous with the El Salvadorian economy. ${ }^{29}$

I also compute the cyclical components using the BK and CF filters. Similar to the results found under the HP filter, results here indicate that remittances are pro-cyclical with the United States business cycle while there is no statistically significant evidence that remittances are either pro- or counter-cyclical with business fluctuations in El Salvador. Under the polynomial fitting model, remittances are neither pro- or counter-cyclical with United States business cycle. With respect to El Salvadorian economy, remittances seem to be pro-cyclical given that for lags 9-12, the correlation coefficient is positive and significant; however, remittances become negatively correlated with El Salvador GPD and significant after lag $k=15$.

Similar to the Mexican analysis, the BN methodology provides better and cleaner results than the rest of the other methodologies. Therefore, I show in this paper that the BN (or for that matter the unobserved components model or state-space model) provides better decomposition of

\footnotetext{
${ }^{29}$ Please note that although remittances are positively correlated with U.S. output for $-6<k<0$, the correlation coefficient turns into negative and significant after $k=5$.
} 
the permanent and transitory components for each series. This, in turn, results in empirical results more aligned to those predicted by economic theory.

\section{Turkey Empirical Analysis}

The cross-correlation analysis for Turkey, under all methodologies, is presented in Figure $10 .^{30}$ The $\mathrm{BN}$ cross-correlation functions indicate that remittances are pro-cyclical, as anticipated, with the Germany business cycle given that both the contemporaneous crosscorrelation coefficient and the asynchronous coefficient with $k=1$ are positive and significant at the $10 \%$ and $5 \%$, respectively. On the other hand, remittances are counter-cyclical with respect to output fluctuations in Turkey given the negative and statistically significant (1\% level) asynchronous cross-correlation coefficient with $k=-1$. However, this last empirical result has a few caveats. Both the cross-correlation coefficients with $k=-2$ and $k=13$ are positive and significant at the $5 \%$ and $1 \%$ level, respectively. Clearly, these opposing results indicate again that the altruism and self-interest motives are contemplated by Turkish migrants settled in Germany. $^{31}$

I again employ a battery of band-pass filters and a polynomial fitting model to compare and contrast my BN empirical results. The first band-pass filter that I use is the HP filter and results under the HP indicate that remittances are counter-cyclical with Germany's output while there is no statistically significant evidence that remittances are either pro- or counter-cyclical with business fluctuations in Turkey. This implies that remittances are asynchronous with the home country: Turkey.

I also compute the cyclical components using the BK and CF filters, and the polynomial fitting model. Similar to the results found under the HP band-pass filter, results here indicate that remittances are counter-cyclical with Germany's business cycle. With respect to Turkish GDP, the BK and CF filters, and the polynomial fitting model provide no statistically significant evidence that remittances are either pro- or counter-cyclical with business fluctuations in Turkey. Similar to the Mexican and El Salvadorian analysis, the BN methodology provides better and cleaner results than the rest of the other methodologies. Therefore, I show again in this paper that the $\mathrm{BN}$ decomposition is superior and as a result the empirical results provided here for Turkey are more aligned to those predicted by economic theory.

\footnotetext{
${ }^{30}$ See footnote 25 .

${ }^{31}$ Similar results were obtained for El Salvador.
} 


\section{Structural Breaks in Remittances to Mexico}

The migration trends between Mexico and the United States have changed dramatically over the last few decades, especially after the Immigration Reform and Control Act (IRCA) that took place in late-1986. Clearly, changes in migration flows have a significant impact on the amount of remittances going back to Mexico from the United States. Furthermore, Banco de Mexico overhauled its methodology by which it collects remittance data in late 2002 in an attempt to better track such international flows given their importance to the Mexican economy. ${ }^{32}$ Both of these events have a significant impact on the behavior of the remittances time series. In fact, one might suspect that these two events might represent structural breaks.

In order to explore this possibility, I break the remittances to Mexico time series into three sub-periods: (1) 1960:Q1-1986:Q4 (pre-IRCA); (2) 1987:Q1-2002:Q4 (post-IRCA and preBanxico); and (3) 2003:Q1-2008:Q4 (post-Banxico). I then estimate the BN cycle under each period and compute the cross-correlation functions between these $\mathrm{BN}$ cycles and output fluctuations. ${ }^{33}$ The sub-sample BN cycles are reported in Figure 7 while the corresponding cross-correlation functions are reported in Figure 10. Taking IRCA as a single structural break, I find that remittances are negatively correlated (counter-cyclical) to both Mexico's and the United States output prior to IRCA and remittances are asynchronous to both output series after IRCA was implemented. The results, pre-IRCA, are much aligned to the results I obtain for the entire sample.

Once I consider the change in methodology by Banco de Mexico as a single break in the remittance time series, the empirical results indicate that remittances tend to be counter-cyclical with both output series prior to 2002:Q4 while pro-cyclical to both output series after 2003:Q1. Again, the empirical results, pre-Banxico, are much aligned to those obtained for the full sample while the results post-Banxico are practically the opposite to those obtain in the full sample.

Considering both events as structural changes, I again obtain that remittances are countercyclical to both GDP series under the first portion 1960:Q1-1986:Q4 (pre-IRCA). Then, remittances are asynchronous during the 1987:Q1-2002:Q4 period (post-IRCA and pre-Banxico)

\footnotetext{
${ }^{32}$ See Canas et al 2007 for more details behind the change in methodology by Banco de Mexico.

${ }^{33}$ Similar to the analysis presented above, I identify, only for the remittances time series, the optimal lag structure, under each sub-sample period, for both polynomials: $\varphi(\mathrm{L})$ and $\theta(\mathrm{L})$ by running all possible combinations of $\operatorname{ARIMA}(p, 1, q)$ models allowing $p$ and $q$ to vary between zero and twelve. For brevity reasons, I do not provide the optimal lag structure here nor the regressions results but they are available upon request.
} 
to fluctuations in both output series. Lastly, for the post-Banxico period, that is for the time period 2003:Q1-2008:Q4, remittances are pro-cyclical with both the Mexican and the United States economies.

Once structural breaks are introduced into the analysis, remittances continue to be countercyclical with the Mexican business cycle in most of the cases under consideration. This is aligned to the results obtained under the full sample analysis summarized above. On the other hand, remittances, in some cases, turned out to be pro-cyclical with the United States GDP fluctuations contrary to the results obtained under the full sample analysis, as expected by economic theory. This is an improvement from the full sample results where remittances resulted counter-cyclical to United States output fluctuations.

\section{Concluding remarks and future research}

To conclude, remittances are increasingly becoming a more important source of income to many developing economies. Therefore, it is important to understand the dynamics behind remittances and whether remittances are pro- or counter-cyclical with output in both source and home countries. In this paper, I propose to use a state-space model (via the BN decomposition) to decompose remittances and output series into permanent trend and stationary cyclical components for Mexico, El Salvador, and Turkey. I then generate cross-correlations using the stationary cyclical components to determine if remittances are related to output series. Results indicate that remittances are counter-cyclical with respect to the home country (i.e. Mexico, El Salvador, and Turkey) while pro-cyclical with the fluctuations of output in the source country (i.e. United States and Germany). For comparison purposes, I also performed similar econometric analysis under the HP, BK, and CF band-pass filters and a polynomial fitting model. Empirical results under these alternative methodologies, similar to results in previous studies, generally contradict economic theory with respect to synchronization of remittances to home and source countries. In some other instances, such alternative methodologies provide inconclusive results

As in any other research project, there are several shortfalls and caveats in the analysis presented here. First, the econometric analysis presented above assumes that output fluctuations are symmetric. $^{34}$ Recent research has shown that recessions and expansions are not symmetric and therefore models that attempt to decompose time series into trend and cycle need to account

\footnotetext{
${ }^{34}$ A similar argument could be made for the remittance time series.
} 
for such phenomena. ${ }^{35}$ As a result, it would be useful to incorporate non-linearities into the above model to see if the empirical results hold or not. Another issue not addressed in the paper is the fact that it has been widely documented that there is a strong economic synchronization between the United States and Mexico. ${ }^{36}$ This potential issue is not addressed in this paper and needs to be addressed in future research.

\footnotetext{
${ }^{35}$ See the work on State-Space Models with Markov-Switching such as Hamilton [1989], Diebold \& Rudebusch [1996], Beaudry \& Koop [1993], Kim and Murray [2002].

${ }^{36}$ See footnote 2 .
} 


\section{References}

Acosta, Pablo A., Cesar Calderon, Pablo Fajnzylber, and Humberto Lopez (2007a). "The Impact of Remittances on Poverty and Human Capital: Evidence from Latin America Household Surveys" World Bank Policy Research Working Paper No. 4247, June.

Acosta, Pablo A., Cesar Calderon, Pablo Fajnzylber, and Humberto Lopez (2007b). "What is the Impact of International Remittances on Poverty and Inequality in Latin America?" World Bank Policy Research Working Paper No. 4249, June

Adams, Richard H, Jr., and John Page (2005). "Do International Migration and Remittances Reduce Poverty in Developing Countries?” World Development, Vol. 33, pp. 1645-1669.

Agarwal, Reena, and Andrew W. Horowitz (2002). "Are International Remittances Altruism or Insurance? Evidence from Guyana Using Multiple-Migrant Households" World Development, Vol. 30, No. 11, pp. 2033-2044.

Apaa-Okello, Jimmy, and Francis Anguyo (2006). "The Cyclical Implications of Immigrant Workers' Remittances to Uganda” Bank of Uganda, Working Paper, November 2006.

Baxter, Marianne, and Robert W. King (1997). "Measuring Business Cycles: Approximate Band-Pass Filters for Economic Time Series" NBER Working Paper 5022.

Beaudry, Paul, and Gary Koop (1993). "Do recessions permanently change output?" Journal of Monetary Economics 31:149-163

Beveridge, Stephen, and Charles R. Nelson (1981). "A New Approach to Decomposition of Economic Time Series into Permanent and Transitory Components with Particular Attention to Measurement of the "Business Cycle"" Journal of Monetary Economics, Vol. 7, pp. 151-174.

Bora Durdu, Ceyhun, and Sedar Sayan (2008). "Emerging Market Business Cycles with Remittance Fluctuation” Federal Reserve Board, Working Paper, February 2008.

Borraz, Fernando (2005). "Assessing the Impact of Remittances on Schooling: The Mexican Experience" Global Economy Journal 5(1): 1-30.

Canas, Jesus, Roberto Coronado and Pia M. Orrenius (2007). "U.S.-Mexico Remittances: Recent Trends and Measurement Issues," in Migration, Trade and Development: Conference Proceedings, James Hollifield, Pia Orrenius and Thomas Osang, eds., Federal Reserve Bank of Dallas, 2007.

Chiquiar, Daniel and Manuel Ramos-Francia (2004). "Bilateral Trade and Business Cycle Synchronization: Evidence from Mexico and United States Manufacturing Industries" Banco de México: Working Paper 2004-05.

Chiquiar, Daniel and Manuel Ramos-Francia (2004). "A Note on Mexico and U.S. Manufacturing Industries' Long-term Relationship” Banco de México: Working Paper 2008-08. 
Christiano, Lawrence J. and Fitzgerald, Terry J. (2003). "The Band Pass Filter" International Economic Review, 44(2):435-65.

Clark, Peter K. (1987). "The Cyclical Component of U.S. Economic Activity" Quarterly Journal of Economics, Vol. 102, No. 4, pp. 797-814.

Cogley, Timothy, and James N. Nason (1995). "Effects of Hodrick-Prescott filter on trend and difference stationary time series: Implications for business cycle research" Journal of Economic Dynamics and Control, Vol. 19, pp. 253-278.

Cox Edwards, Alejandra, and Manuelita Ureta [2003]. "International migration, remittances, and schooling: Evidence from El Salvador” NBER Working Paper 9766.

Cuadra, Gabriel (2008). "Hechos Estilizados del Ciclo Económico en México" Banco de México: Working Paper 2008-14.

de la Briere, Benedicte, Elisabeth Sadouleth, Alain de Janvry, and Sylvie Lambert (2002). "The Roles of Destination, Gender, and Household Composition in Explaining Remittances: An Analysis for the Dominican Sierra" Journal of Development Economics, Vol. 68, pp. 309-328.

Demirgüç-Kunt, Asli, Ernesto López-Córdova, María Soledad Martinez Pería, and Christopher Woodruff (2007). "Remittances and Banking Services: Evidence from Mexico" Mimeo, University of California, San Diego, April.

Diebold, Francis X., and Glenn D. Rudebusch (1996). "Measuring business cycles: A modern perspective" The Review of Economics and Statistics 78:67-77

Elliott, Graham, Rothenberg, Thomas J., and James H. Stock (1996). "Efficient Tests for an Autoregressive Unit Root" Econometrica, Econometric Society, vol. 64(4), pages 813-36, July.

Esquivel, Gerardo, and Alejandra Huerta-Pineda (2007). "Remittances and Poverty in Mexico: A Propensity Score Matching Approach" Integration and Trade Journal, forthcoming.

Gupta, Poonam (2005). "Macroeconomic Determinants of Remittances: Evidence from India" International Monetary Fund Working Paper No. 05/224, December.

Giuliano, Paola, and Martha Ruiz-Arranz (2009). "Remittances, financial development, and growth" Journal of Development Economics, 90: 144-152

Hamilton, James D. (1989). "A new approach to the economic analysis of nonstationary time series and the business cycle" Econometrica 57:357-384

Hanson, Gordon H., and Christopher Woodruff (2003). "Emigration and Educational Attainment in Mexico" Mimeo, University of California, San Diego, April. 
Hodrick, Robert J., and Edward C. Prescott (1997). "Postwar U.S. Business Cycles: An Empirical Investigation” Journal of Money, Credit and Banking, Vol. 29, No. 1, pp. 1-16.

Kim, Chang-Jin, and Christian J. Murray (2002). "Permanent and Transitory Components of Recessions" Empirical Economics 27: 163-183.

Lopez Cordova, Ernesto (2004). "Globalization, Migration and Development: The Role of Mexican Migrant Remittances” Econometric Society 2004 Latin American Meetings 82, Econometric Society.

Lueth, Erik, and Marta Ruiz-Arranz (2007). "Are Workers' Remittances a Hedge Against Macroeconomic Shocks? The Case of Sri Lanka" IMF Working Paper No. 07/22, Washington, DC: IMF.

Magnusson, Kristin (2009). "The Impact of U.S. Regional Business Cycles on Remittances to Latin America"SSE/EFI Working Papers in Economics and Finance No. 710, February.

Mora Rivera, Jose Jorge (2005). "The Impact of Migration and Remittances on Distribution and Source of Income: The Mexican Rural Case" Presented at United Nations Expert Group Meeting on International Migration and Development, United Nations Secretariat, New York (July 6-8).

Morley, James C., Charles R. Nelson, and Eric Zivot (2003). "Why are the Beveridge-Nelson and Unobserved-Components Decompositions of GDP so Different?" Review of Economics and Statistics, Vol. 85, No. 2, pp. 235-243.

Murray, Christian J. (2003). "Cyclical Properties of Baxter-King Filtered Time Series," The Review of Economics and Statistics 85: 472-476.

Orrenius, Pia M., Zavodny, Madeline, Canas, Jesus and Roberto Coronado (2009). "Do Remittances Boost Economic Development? Evidence from Mexican States" Federal Reserve Bank of Dallas, working paper.

Rapaport, Hillel, and Frédéric Docquier (2006). "The Economics of Migrant's Remittances" Handbook of the Economics of Giving, Altruism and Reciprocity, Volume 2, Edited by SergeChristophe Kolm and Jean Mercier Ythier.

Ratha, Dilip (2003). "Workers' Remittances: An Important and Stable Source of External Development Finance" (Chapter 7) in Global Development Finance: Striving for Stability in Development Finance, Washington, DC: World Bank, pp. 157-175.

Ratha, Dilip and Zhimei Xu (2008). "Migration and remittances factbook 2008" Washington, DC: World Bank.

Roache, Shaum K. and Ewa Gradzka (2007) "Do Remittances to Latin America Depend on the U.S. Business Cycle?” IMF Working Paper No. 07/273, Washington, DC: IMF. 
Sayan, Sedar (2006). "Business Cycles and Workers' Remittances: How do Migrant Workers Respond to Cyclical Movements of GDP at Home?" IMF Working Paper No. 06/52, Washington, DC: IMF.

Sayan, Sedar, and Ayca Tekin-Koru (2007). "Remittances, Business Cycles and Poverty: The Recent Turkish Experience" MPRA Paper No. 6029.

Vargas-Silva, Carlos (2009) "Are Remittances manna from heaven? A look at the business cycle properties of remittances" North American Journal of Economics and Finance, forthcoming.

Vargas-Silva, Carlos, and Peng Huang (2006). "Macroeconomic Determinants of Workers' Remittances: Host versus Home Country's Economic Conditions" Journal of International Trade and Economic Development, Vol. 15, No. 1, pp. 81-99.

Woodruff, Christian, and Rene Zenteno (2001). "Remittances and Microenterprises in Mexico" UCSD Working Paper. 
Table 1. Importance of Remittances, selected dates

\begin{tabular}{lcccccc} 
Mexico & \\
\hline & $\mathbf{1 9 6 0}$ & $\mathbf{1 9 7 0}$ & $\mathbf{1 9 8 0}$ & $\mathbf{1 9 9 0}$ & $\mathbf{2 0 0 0}$ & $\mathbf{2 0 0 8}$ \\
\hline \hline Remittances (Billions of US\$) & 0.084 & 0.182 & 0.699 & 2.494 & 6.573 & 25.137 \\
Share of GDP & $0.7 \%$ & $0.5 \%$ & $0.4 \%$ & $1.0 \%$ & $1.1 \%$ & $2.8 \%$ \\
Share of FDI & $62.7 \%$ & $57.6 \%$ & $33.5 \%$ & $94.7 \%$ & $36.5 \%$ & $135.2 \%$ \\
Share of Total Exports & n.a. & n.a. & $3.9 \%$ & $6.1 \%$ & $4.0 \%$ & $9.2 \%$ \\
Share of Oil Exports & n.a. & n.a. & $6.7 \%$ & $24.7 \%$ & $40.7 \%$ & $58.4 \%$ \\
Share of Manufacturing Exports & n.a. & n.a. & $12.6 \%$ & $9.0 \%$ & $4.5 \%$ & $11.4 \%$ \\
\hline
\end{tabular}

\begin{tabular}{lccccc} 
El Salvador & \\
\hline & $\mathbf{1 9 9 1}$ & $\mathbf{1 9 9 5}$ & $\mathbf{2 0 0 0}$ & $\mathbf{2 0 0 5}$ & $\mathbf{2 0 0 8}$ \\
\hline Remittances (Billions of US\$) & 0.7901 & 1.061 & 1.756 & 3.017 & 3.788 \\
Share of GDP & $14.9 \%$ & $11.2 \%$ & $13.3 \%$ & $17.7 \%$ & $17.1 \%$ \\
Share of FDI & n.a. & n.a. & $89.0 \%$ & $72.4 \%$ & $56.5 \%$ \\
Share of Total Exports & $109.0 \%$ & $64.2 \%$ & $59.5 \%$ & $88.3 \%$ & $83.3 \%$ \\
Share of Manufacturing Exports & $578.0 \%$ & $164.1 \%$ & $108.8 \%$ & $165.7 \%$ & $196.4 \%$ \\
Share of Total Imports & $52.1 \%$ & $31.9 \%$ & $35.4 \%$ & $45.1 \%$ & $38.8 \%$ \\
\hline
\end{tabular}

\begin{tabular}{lcccccc} 
Turkey & & & \\
\hline & $\mathbf{1 9 6 4}$ & $\mathbf{1 9 7 0}$ & $\mathbf{1 9 8 0}$ & $\mathbf{1 9 9 0}$ & $\mathbf{2 0 0 0}$ & $\mathbf{2 0 0 7}$ \\
\hline \hline Total remittances (Millions of US\$) & 0.009 & 0.273 & 2.071 & 3.246 & 4.560 & 1.209 \\
Share of GDP & $0.1 \%$ & $1.5 \%$ & $3.0 \%$ & $2.2 \%$ & $2.3 \%$ & $0.2 \%$ \\
Share of Total Exports & 2.2 & 46.4 & $71.2 \%$ & $25.0 \%$ & $16.4 \%$ & $1.1 \%$ \\
Share of Total Imports & 1.7 & 28.8 & $26.2 \%$ & $14.6 \%$ & $8.4 \%$ & $0.7 \%$ \\
\hline
\end{tabular}

Notes: For Turkey, I report total remittances received by Turkey. However, for the econometric analysis in this paper, I use remittances received from Germany only.

Source: Banco de Mexico, Banco Central de Reserva de El Salvador, and Turkish Statistical Institute 
Table 2. Summary of Current Literature on Remittances and Business Cycles

\begin{tabular}{|c|c|c|c|c|c|}
\hline Paper & Country & Sample & Frequency & Methodology & Results \\
\hline Sayan [2006] & 12 developing countries & $1976-2003$ & Annual & Pol & Ambiguous \\
\hline Apaa-Okello/Anguyo [2006] & Uganda & $1992-2005$ & Annual & $\mathrm{HP} \& \mathrm{CF}$ & Pro-cyclical w/Home \\
\hline Sayan/Tekin-Koru [2007] & Turkey & $1987-2003$ & Quarterly & HP \& Pol & $\begin{array}{l}\text { Pro-cyclical w/Home } \\
\text { and Source }\end{array}$ \\
\hline Lueth/Ruiz-Arranz [2007] & Sri Lanka & $1996-2004$ & Quarterly & VEC & Pro-cyclical w/Home \\
\hline Vargas-Silva [2008] & Mexico & $1981-2006$ & Quarterly & BK \& VAR & $\begin{array}{l}\text { Counter-cyclical } \\
\text { w/Home \& Pro-cyclical } \\
\text { w/Source }\end{array}$ \\
\hline Bora Durdu/Sayan [2008] & Mexico and Turkey & 1980s-2006 & Quarterly & $\mathrm{RBC}$ & $\begin{array}{l}\text { Counter-cyclical } \\
\text { w/Mexico \& Pro-cyclical } \\
\text { w/Turkey }\end{array}$ \\
\hline Roache/Gradzka [2007] & Latin America countries & $1990-2007$ & Quarterly & SS & Ambiguous and weak \\
\hline
\end{tabular}


Table 3. DF-GLS Unit Root Test Results [w/ Constant \& Linear Time Trend]

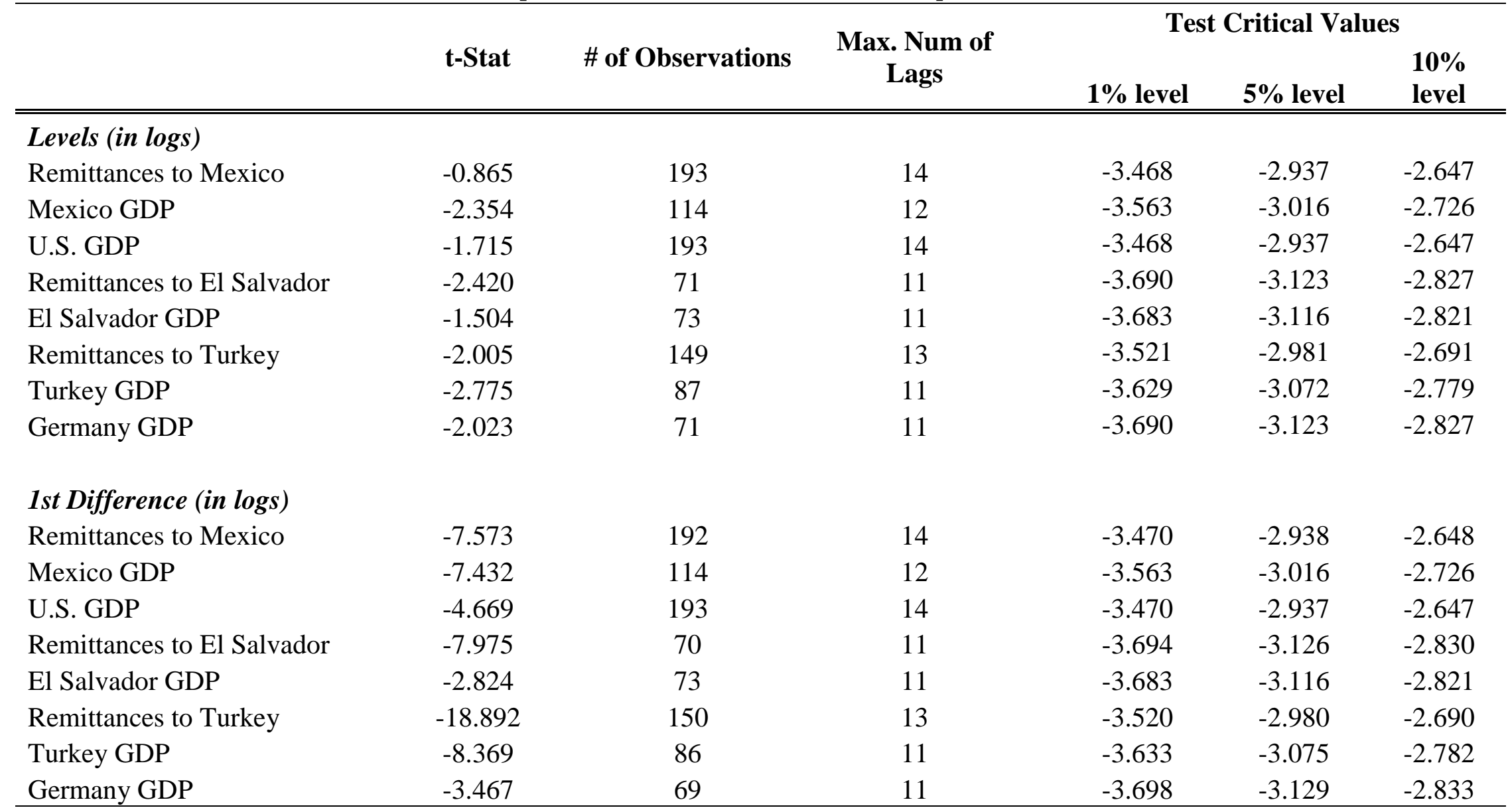

Notes: Data for Mexico GDP corresponds to the period 1980:Q1 - 2008:Q4; for U.S. GDP and Remittances to Mexico corresponds to the period 1960:Q1 - 2008:Q4; for El Salvador GDP corresponds to the period 1990:Q1 - 2008:Q4; for Remittances to El Salvador corresponds to the period 1991:Q1 - 2008:Q4; for Remittances to Turkey corresponds to the period 1971:Q1-2008:Q4; for Turkey GDP corresponds to the period 1987:Q1-2008:Q4; and for Germany GDP corresponds to the period 1991:Q1-2008:Q4. As a robustness check, I also performed the Augmented Dickey-Fuller (ADF) unit root test for all time series and obtain the same results as with the DF-GLS unit root tests shown above. 
Table 4. ARIMA(p,1,q) Regression Results

\begin{tabular}{|c|c|c|c|}
\hline & $\begin{array}{l}\text { Remittances to Mexico } \\
{[p=2, q=0]}\end{array}$ & Mexico GDP $\quad[p=0, q=1]$ & $\begin{array}{l}\text { U.S. GDP } \\
{[p=1, q=0]}\end{array}$ \\
\hline Constant & $\begin{array}{c}0.0196 * * * \\
(0.003)\end{array}$ & \multirow[t]{3}{*}{$\begin{array}{l}0.0060 * * * \\
(0.002)\end{array}$} & $\begin{array}{l}0.0078^{* * * *} \\
(0.001)\end{array}$ \\
\hline$\varphi 1$ & $\begin{array}{c}-0.2841 * * * \\
(0.070)\end{array}$ & & $\begin{array}{c}0.3038 * * * \\
(0.070)\end{array}$ \\
\hline$\varphi 2$ & $\begin{array}{c}-0.2336 * * * \\
(0.071)\end{array}$ & & \\
\hline$\theta 1$ & \multicolumn{3}{|c|}{$\begin{array}{c}0.3398 * * * \\
(0.093)\end{array}$} \\
\hline$\theta 2$ & \multicolumn{3}{|c|}{$\begin{array}{c}0.3128 * * * \\
(0.093)\end{array}$} \\
\hline & $\begin{array}{c}\text { Remittances to El Salvador } \\
{[p=0, q=0]}\end{array}$ & $\begin{array}{c}\text { El Salvador GDP } \\
{[p=0, q=2]}\end{array}$ & $\begin{array}{l}\text { U.S. GDP } \\
{[p=1, q=0]}\end{array}$ \\
\hline Constant & $\begin{array}{c}0.0148 * * \\
(0.006)\end{array}$ & $\begin{array}{l}0.0090 * * * \\
(0.001)\end{array}$ & $\begin{array}{l}0.0078^{* * *} \\
(0.001)\end{array}$ \\
\hline$\varphi 1$ & & & $\begin{array}{l}0.3038^{* * *} \\
(0.070)\end{array}$ \\
\hline \multicolumn{4}{|l|}{$\varphi 2$} \\
\hline$\theta 1$ & & $\begin{array}{c}0.3823 * * * \\
(0.043)\end{array}$ & \\
\hline \multirow[t]{2}{*}{$\theta 2$} & & $\begin{array}{c}0.9243 * * * \\
(0.043)\end{array}$ & \\
\hline & $\begin{array}{l}\text { Remittances to Turkey } \\
\qquad[p=0, q=1] \\
\end{array}$ & $\begin{array}{c}\text { Turkey GDP } \\
{[p=1, q=0]} \\
\end{array}$ & $\begin{array}{c}\text { Germany GDP } \\
{[p=0, q=0]} \\
\end{array}$ \\
\hline Constant & $\begin{array}{l}-0.0068 \\
(0.294)\end{array}$ & $\begin{array}{c}0.0091 * * * \\
(0.003)\end{array}$ & $\begin{array}{c}0.0032 * * * \\
(0.000)\end{array}$ \\
\hline$\varphi 1$ & & $\begin{array}{l}-0.0857 \\
(0.111)\end{array}$ & \\
\hline$\varphi 2$ & & & \\
\hline$\theta 1$ & $\begin{array}{c}-0.6437 * * * \\
(0.000)\end{array}$ & & \\
\hline$\theta 2$ & & & \\
\hline
\end{tabular}

Notes: Data for Mexico GDP is for the period 1980:Q1-2008:Q4 while for U.S. GDP and Remittances to Mexico is for the period 1960:Q12008:Q4; for El Salvador GDP is for the period 1990:Q1-2008:Q4; for Remittances to El Salvador is for the period 1991:Q1-2008:Q4; for Remittances to Turkey is for the period 1971:Q1-2008:Q4; for Turkey GDP is for the period 1987:Q1-2008:Q4; and for Germany GDP is for the period 1991:Q1-2008:Q4. Standard errors are in parenthesis. *** p-value $<0.01$; ** p-value $<0.05$; and $*$ p-value $<0.10$. 
Figure 1. Output and Remittance Time Series for Mexico and EI Salvador
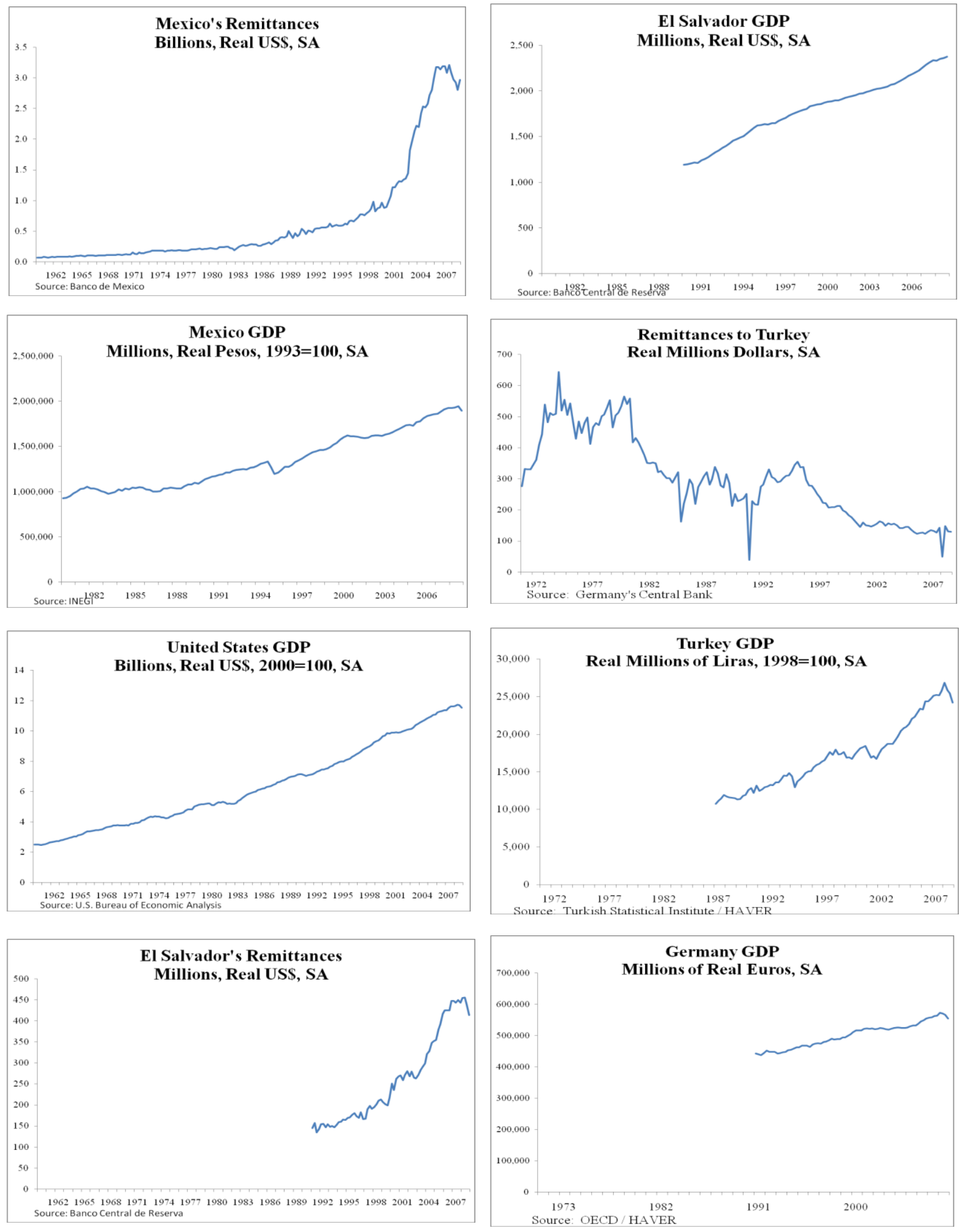
Figure 2. Beveridge-Nelson cyclical components

Remittances to Mexico

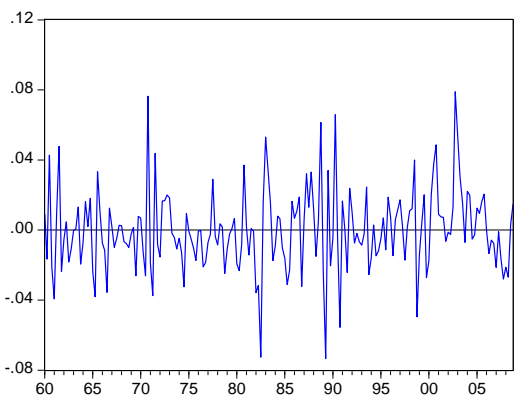

\section{Mexico GDP}

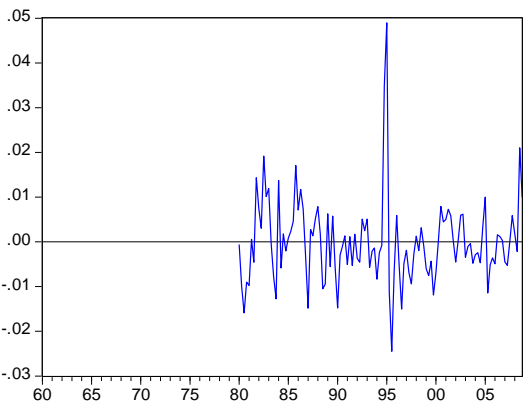

U.S. GDP

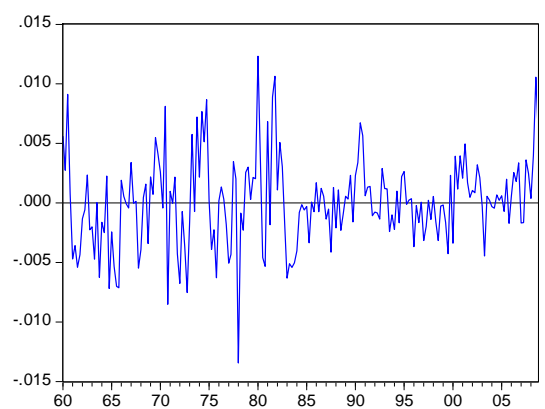

Remittances to El Salvador

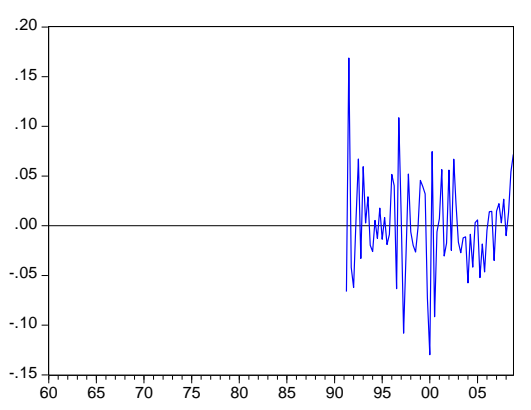

El Salvador GDP

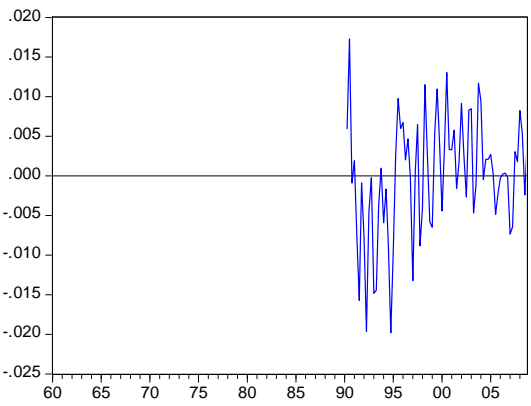

Remittances to Turkey

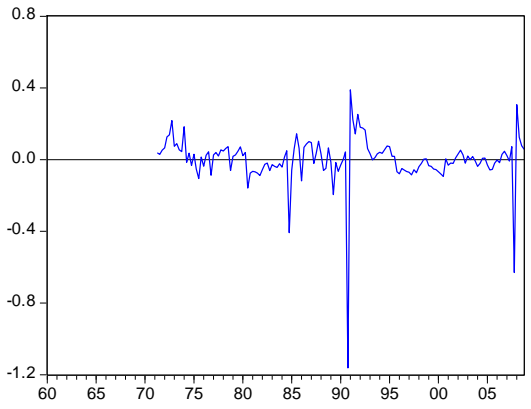

Turkey GDP

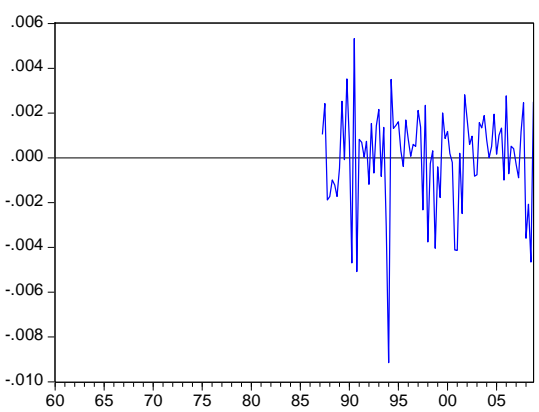

Germany GDP

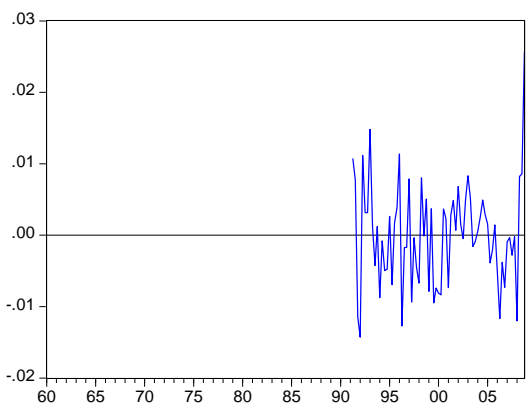


Figure 3. Hodrick-Prescott cyclical components

Remittances to Mexico

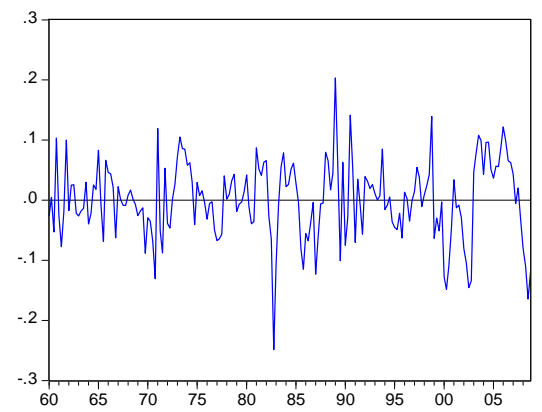

Mexico GDP

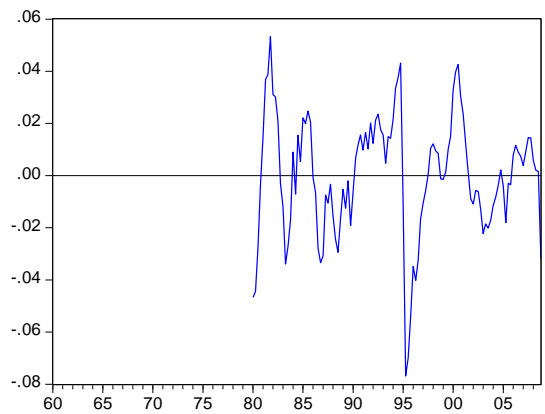

U.S. GDP

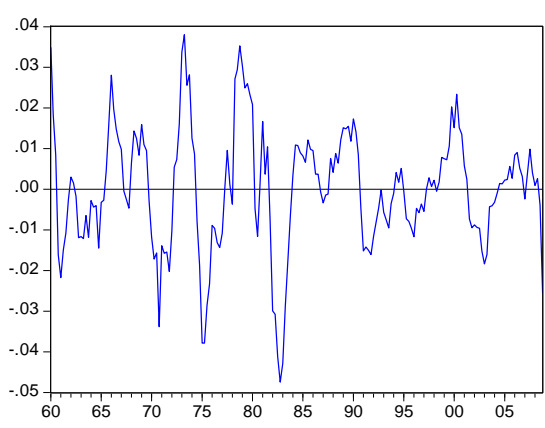

Remittances to El Salvador

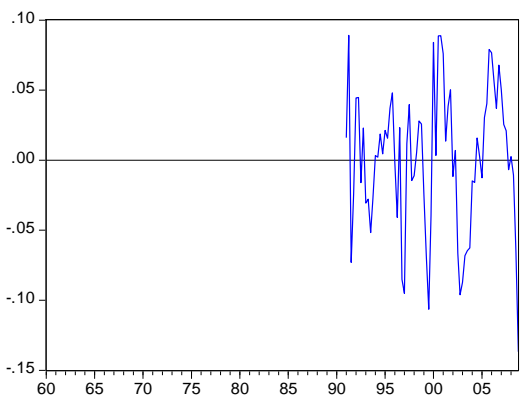

El Salvador GDP

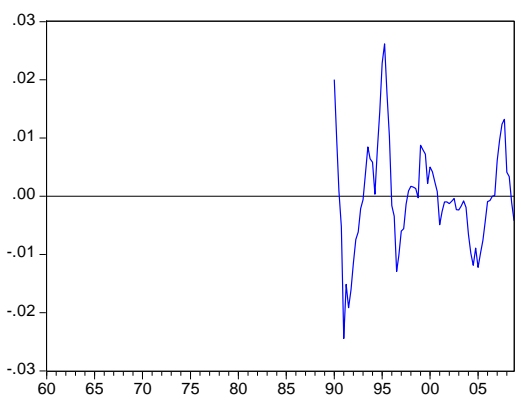

Remittances to Turkey

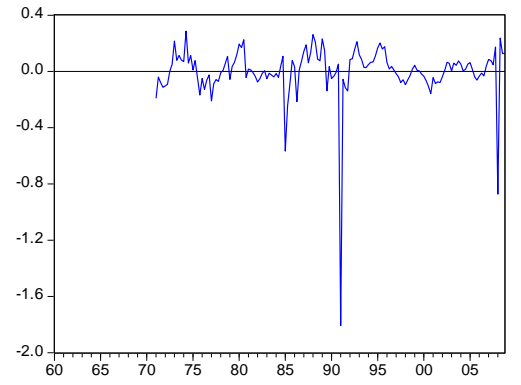

Turkey GDP

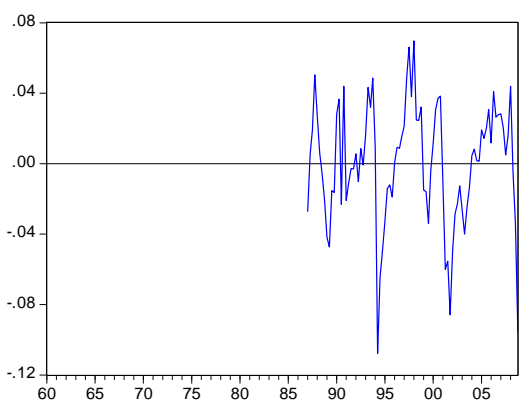

Germany GDP

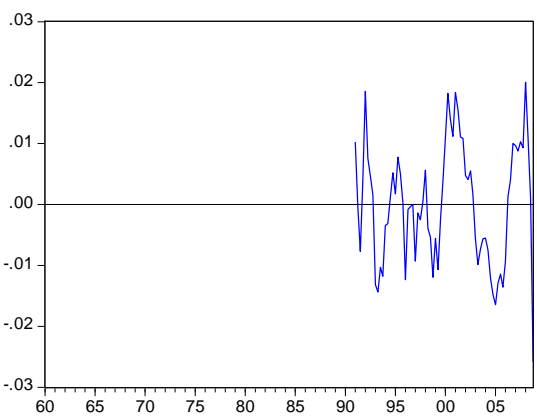


Figure 4. Baxter-King cyclical components

Remittances to Mexico

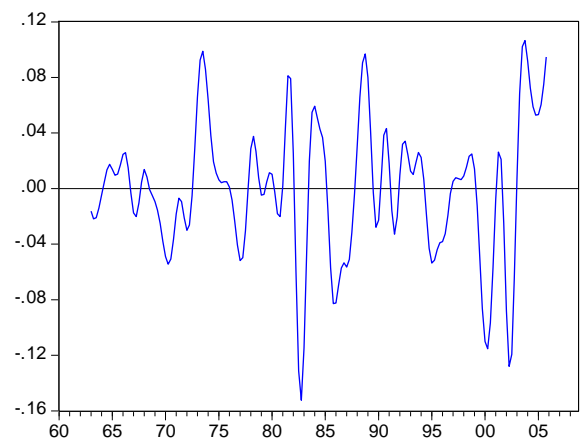

Mexico GDP

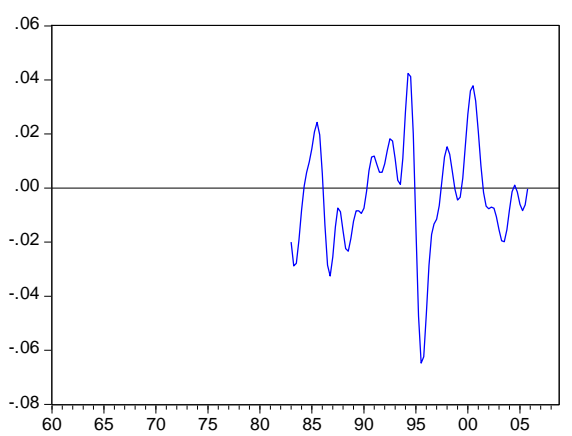

U.S. GDP

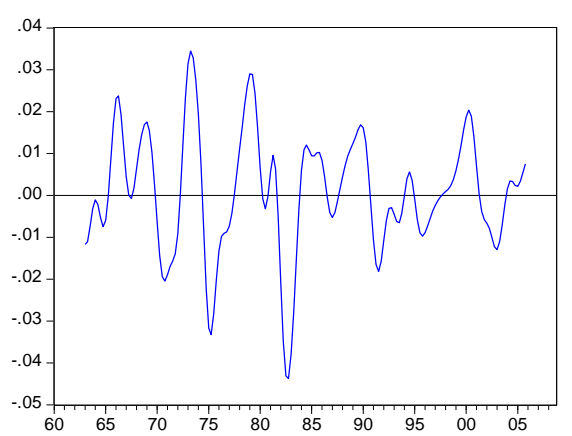

Remittances to El Salvador

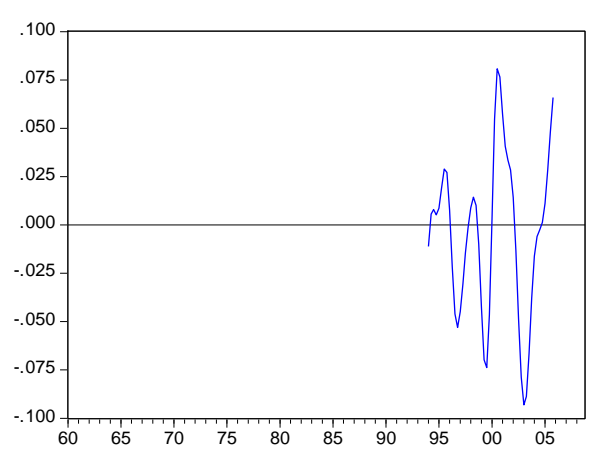

El Salvador GDP

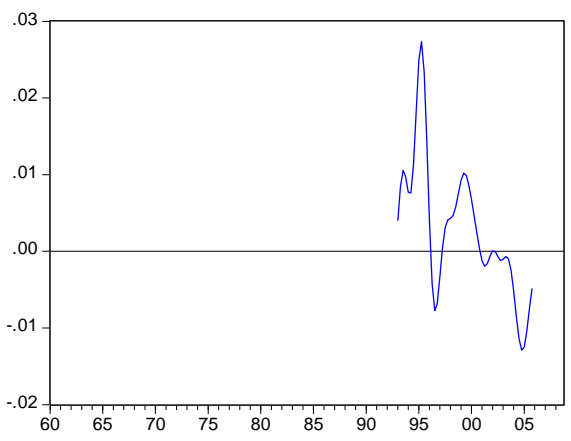

Remittances to Turkey

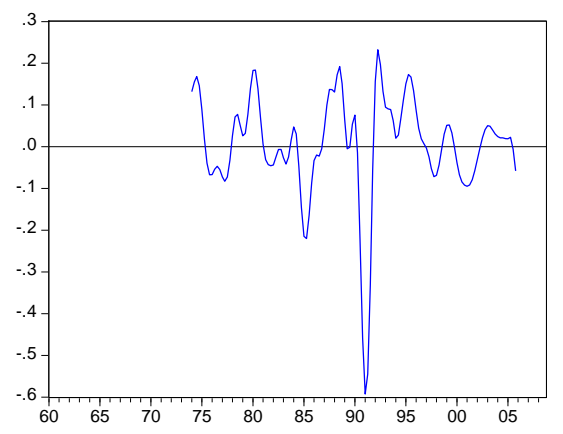

Turkey GDP

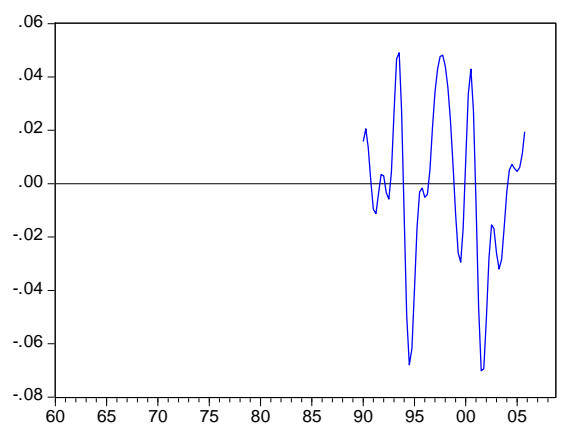

Germany GDP

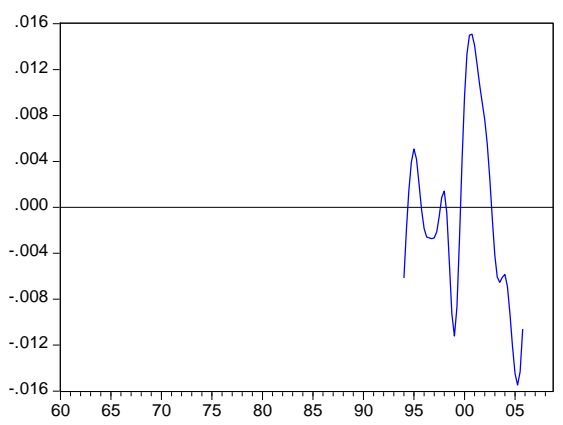


Figure 5. Christiano-Fitzgerald cyclical components

Remittances to Mexico

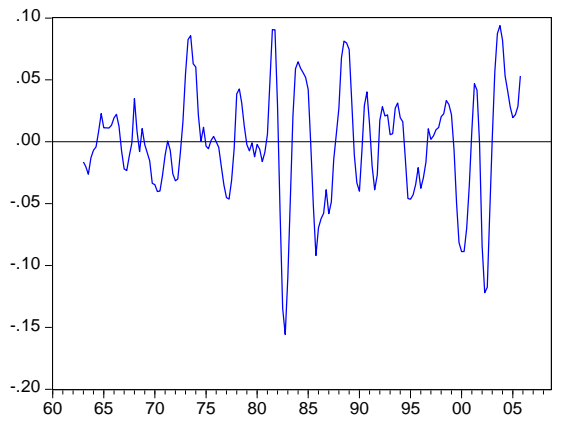

Mexico GDP

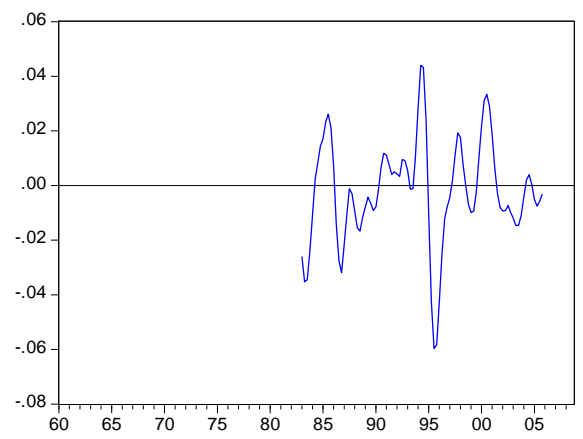

U.S. GDP

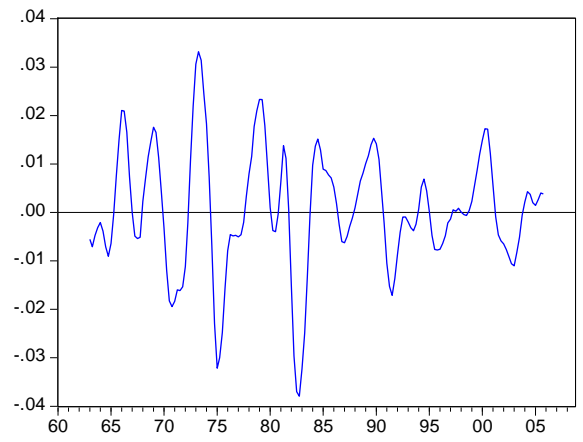

Remittances to El Salvador

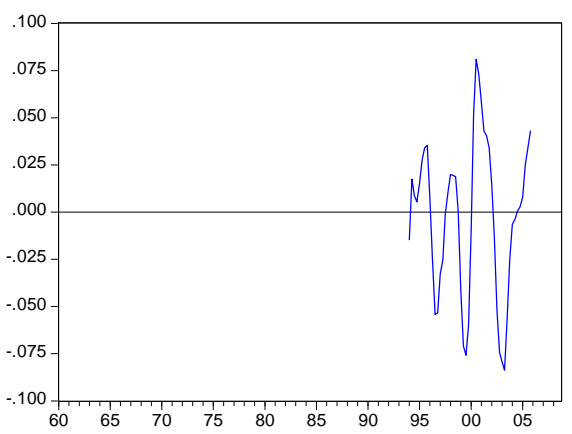

El Salvador GDP

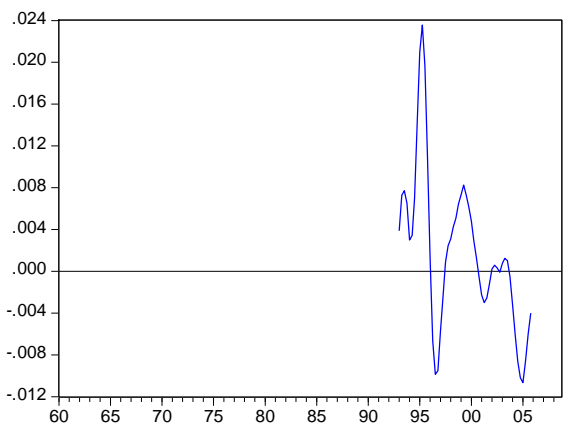

Remittances to Turkey

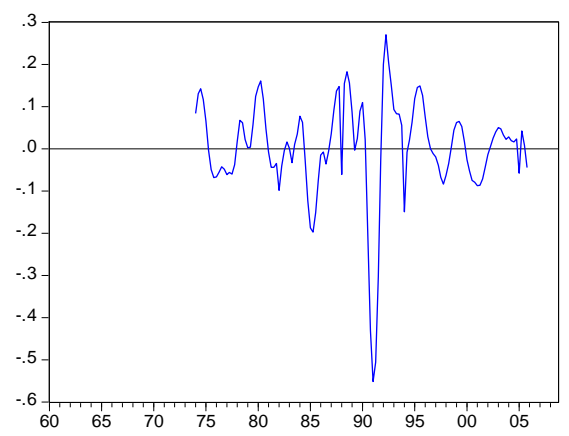

Turkey GDP

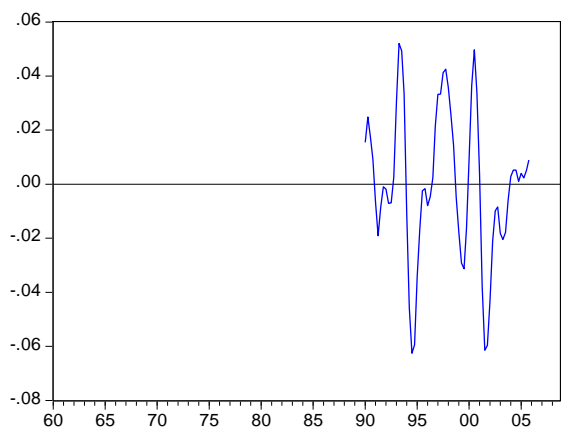

Germany GDP

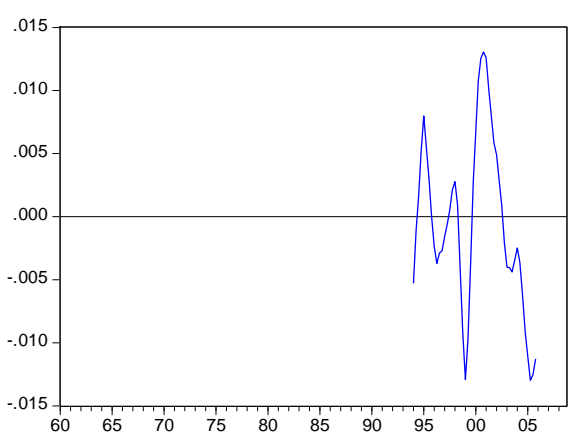


Figure 6. Polynomial fitting model cyclical components

Remittances to Mexico

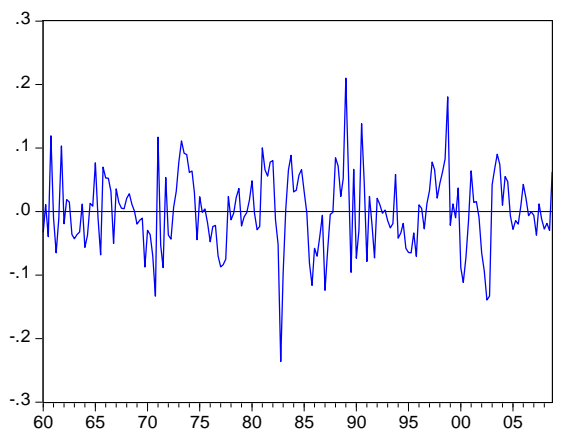

Mexico GDP

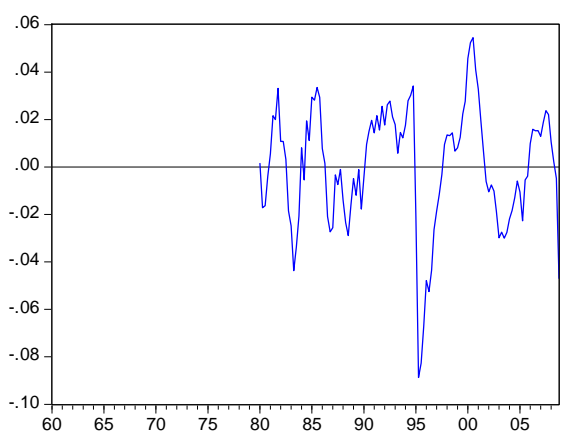

U.S. GDP

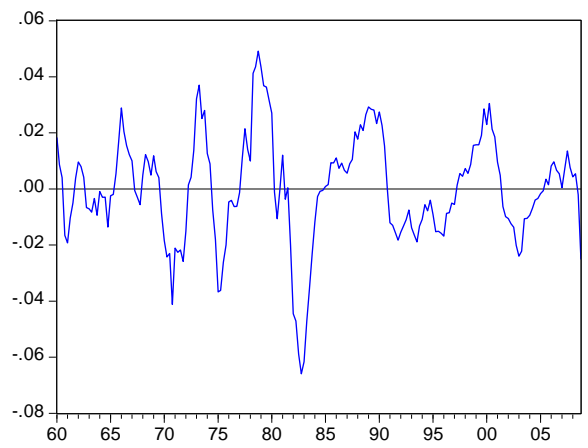

Remittances to El Salvador

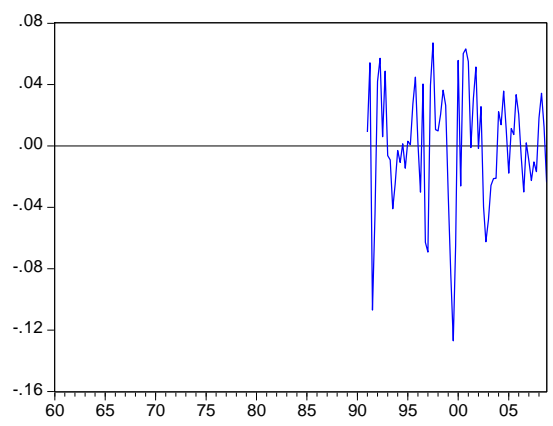

El Salvador GDP

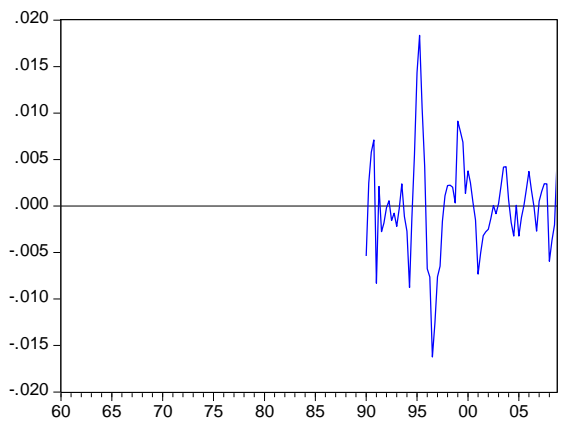

Remittances to Turkey

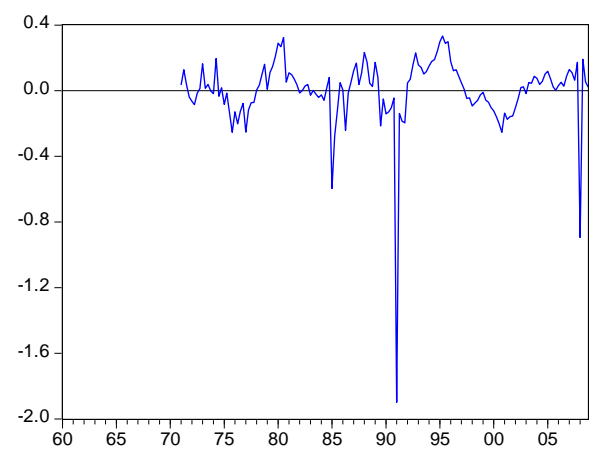

Turkey GDP

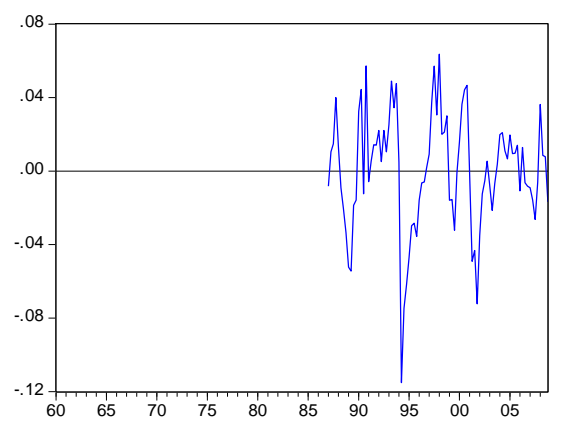

Germany GDP

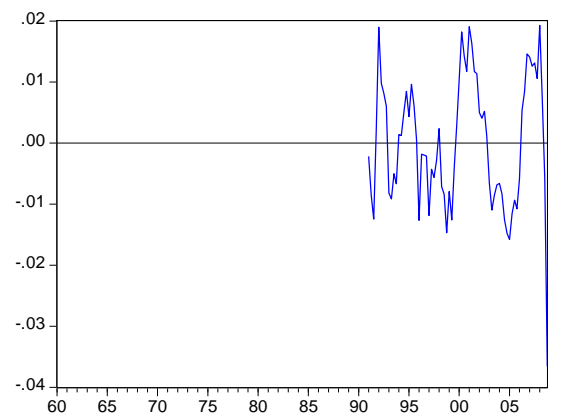


Figure 7. Beveridge-Nelson cyclical components for remittances to Mexico under structural breaks

One Break: IRCA

1960:Q1 - 1986:Q4

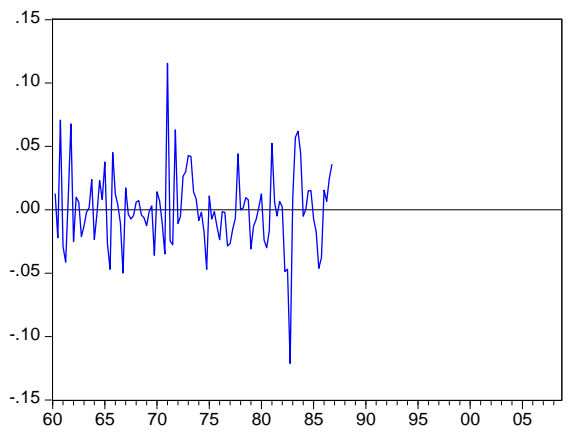

One Break: Banxico

$$
\text { 1960:Q1 - 2002:Q4 }
$$

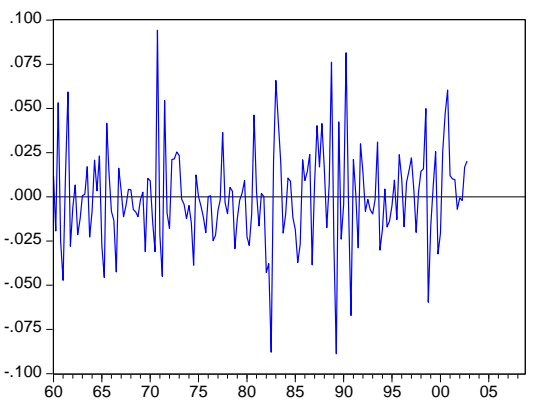

Two Breaks: IRCA \& Banxico

$$
\text { 1960:Q1 - 1986:Q4 }
$$

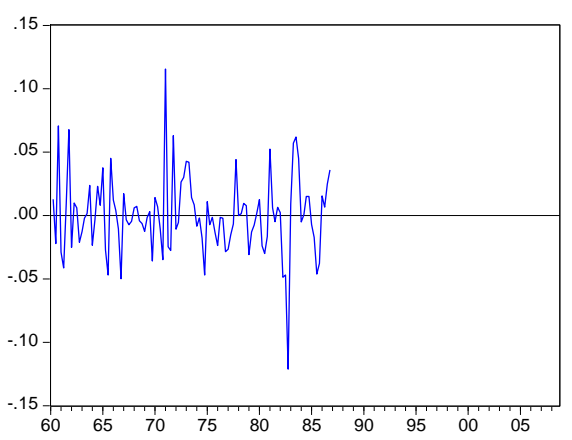

1987:Q1 - 2008:Q4

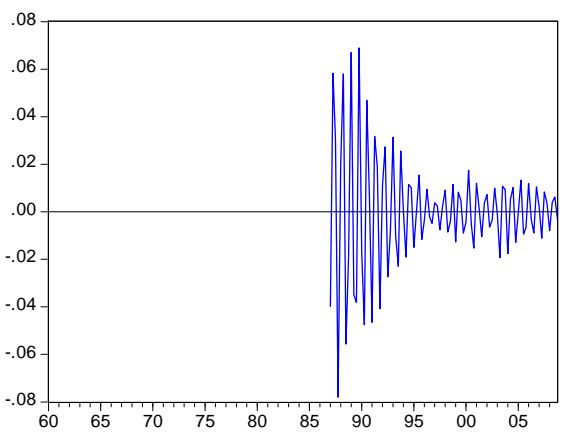

2003:Q1 - 2008:Q4

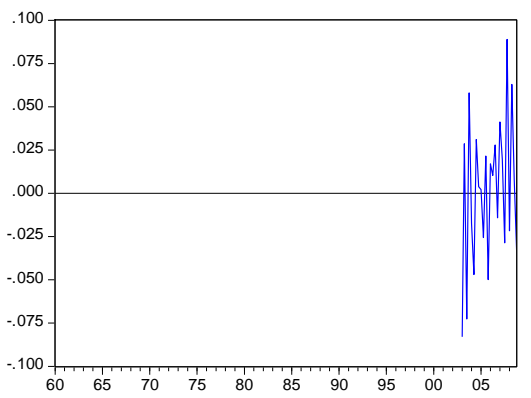

1987:Q1 - 2002:Q4

2003:Q1 - 2008:Q4
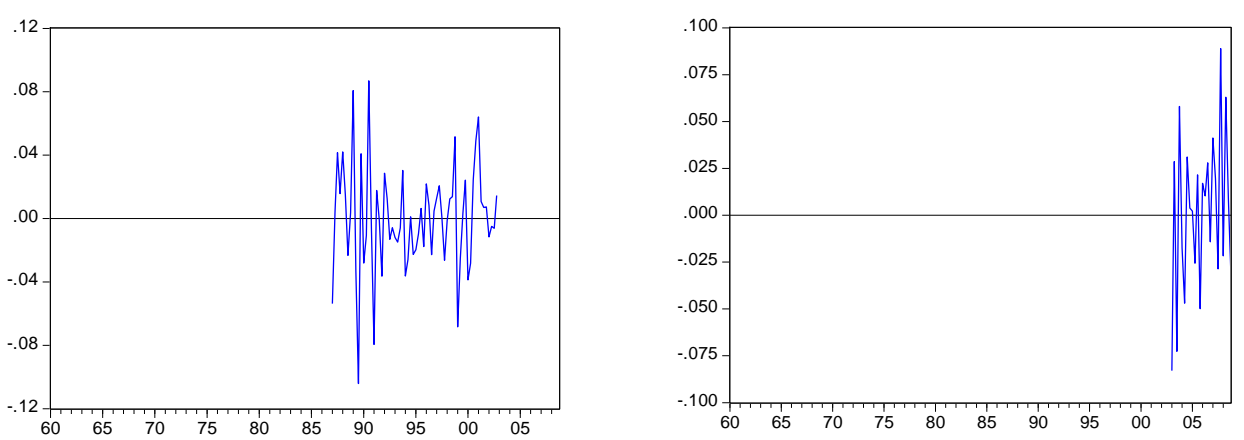
Figure 8. Cross-correlation analysis for Mexico
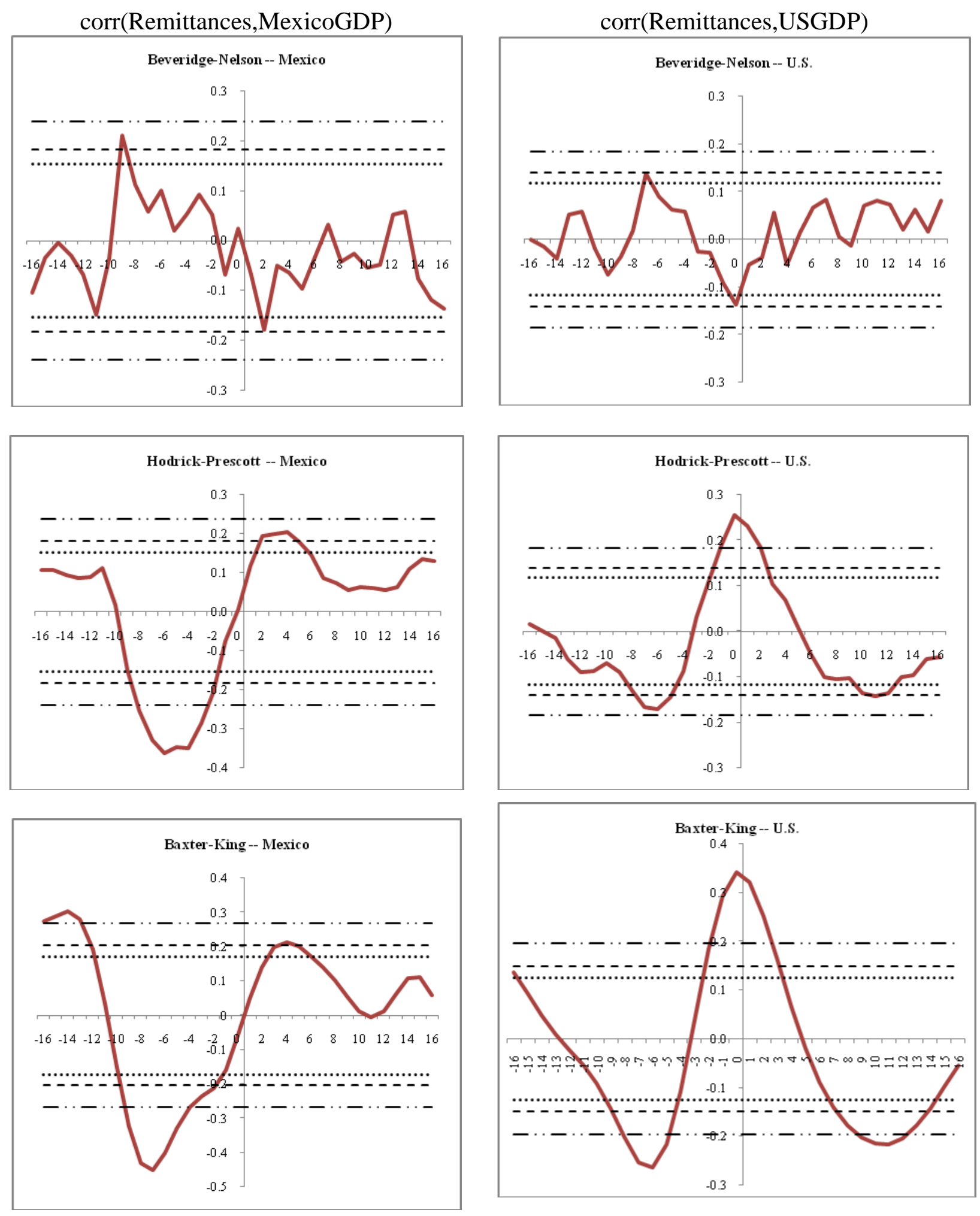

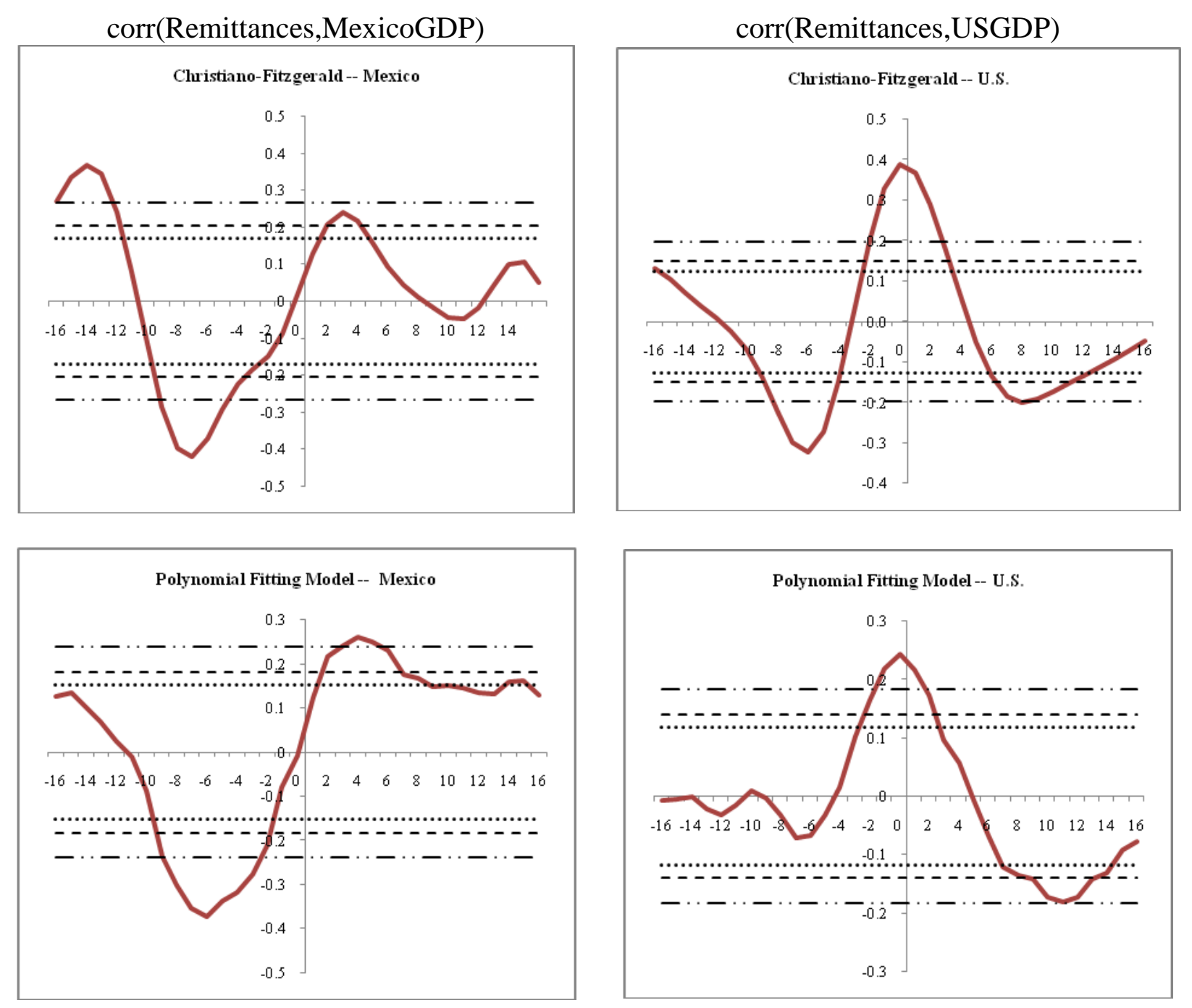
Figure 9. Cross-correlation analysis for EI Salvador
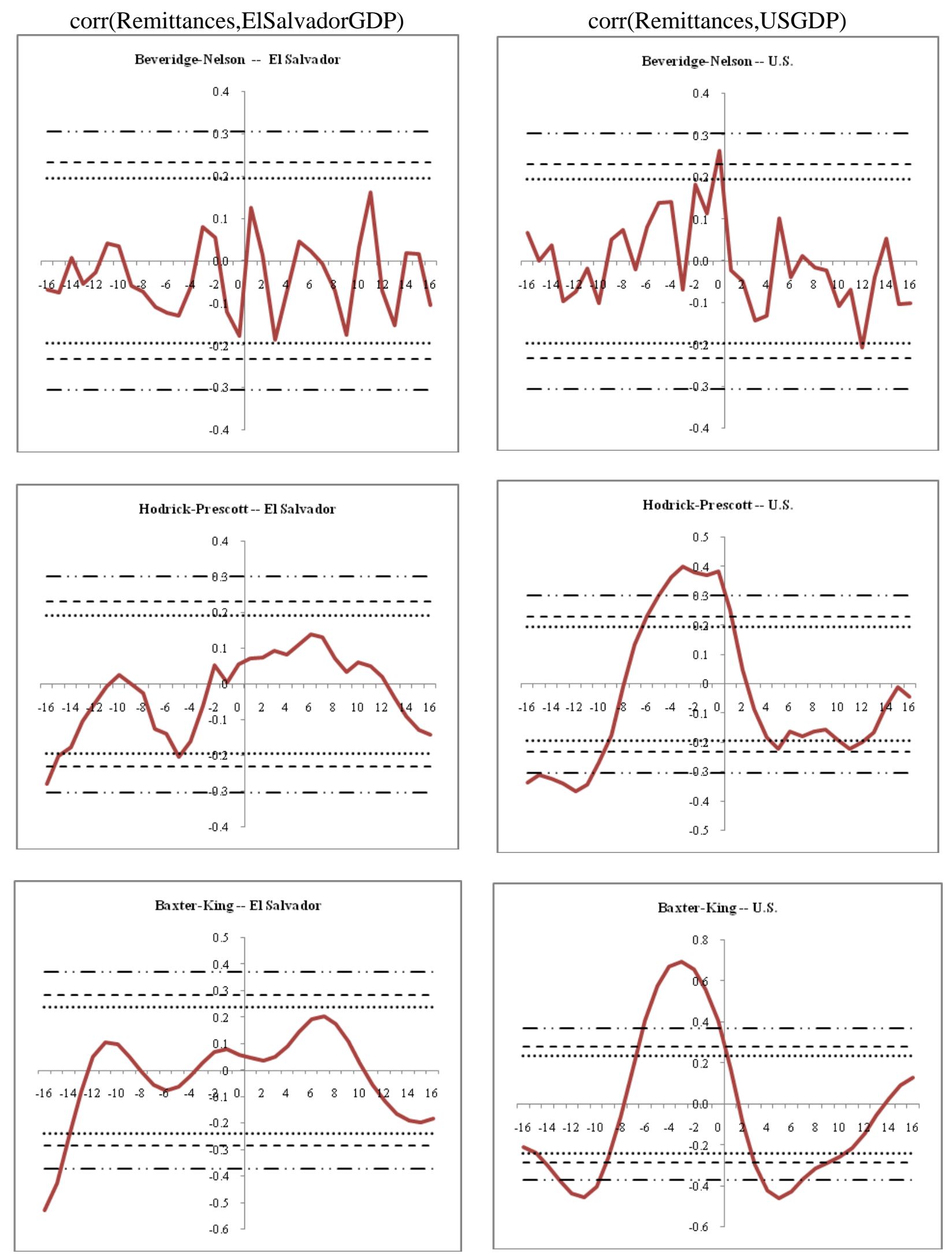

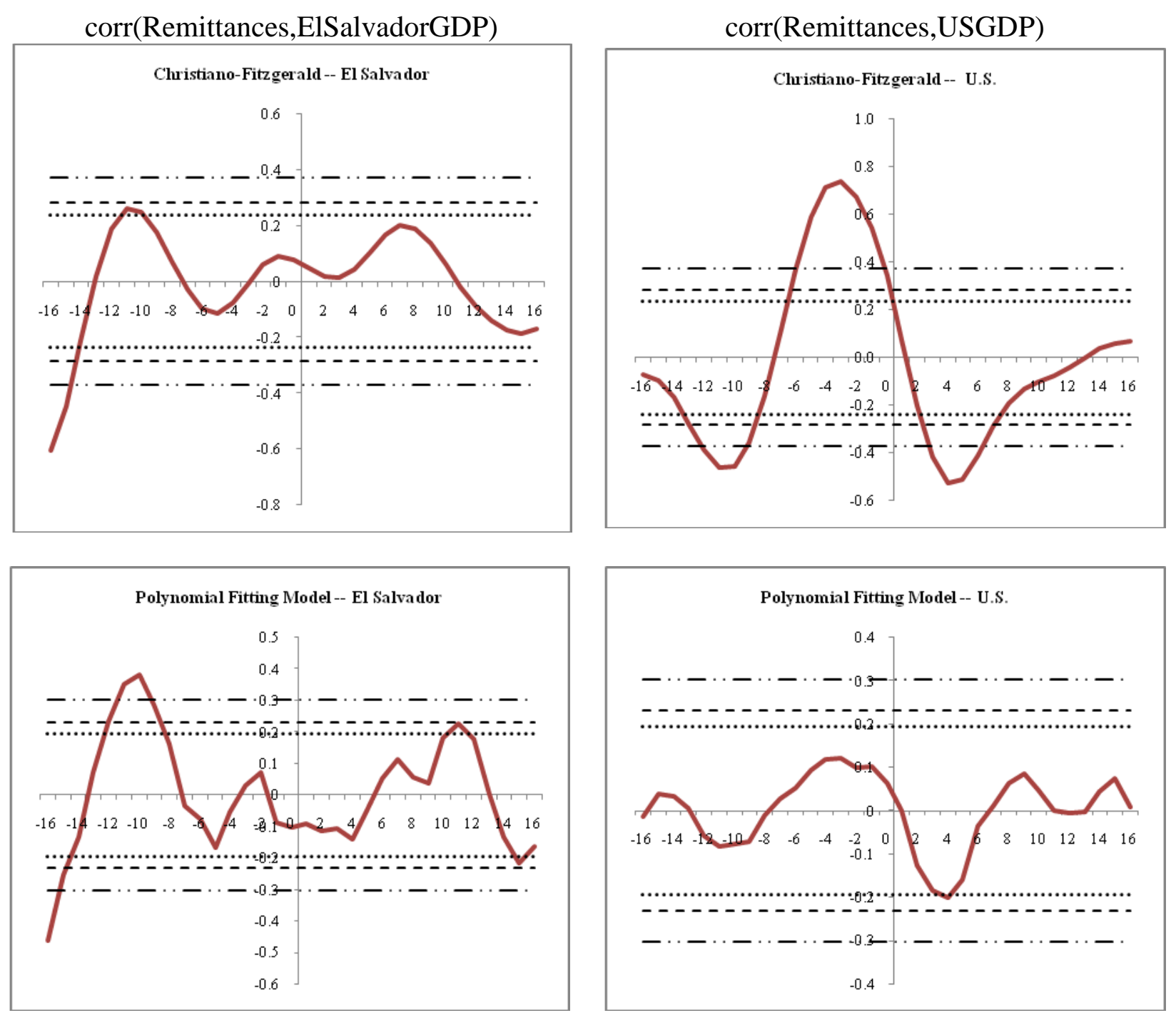
Figure 10. Cross-correlation analysis for Turkey

corr(Remittances,TurkeyGDP)
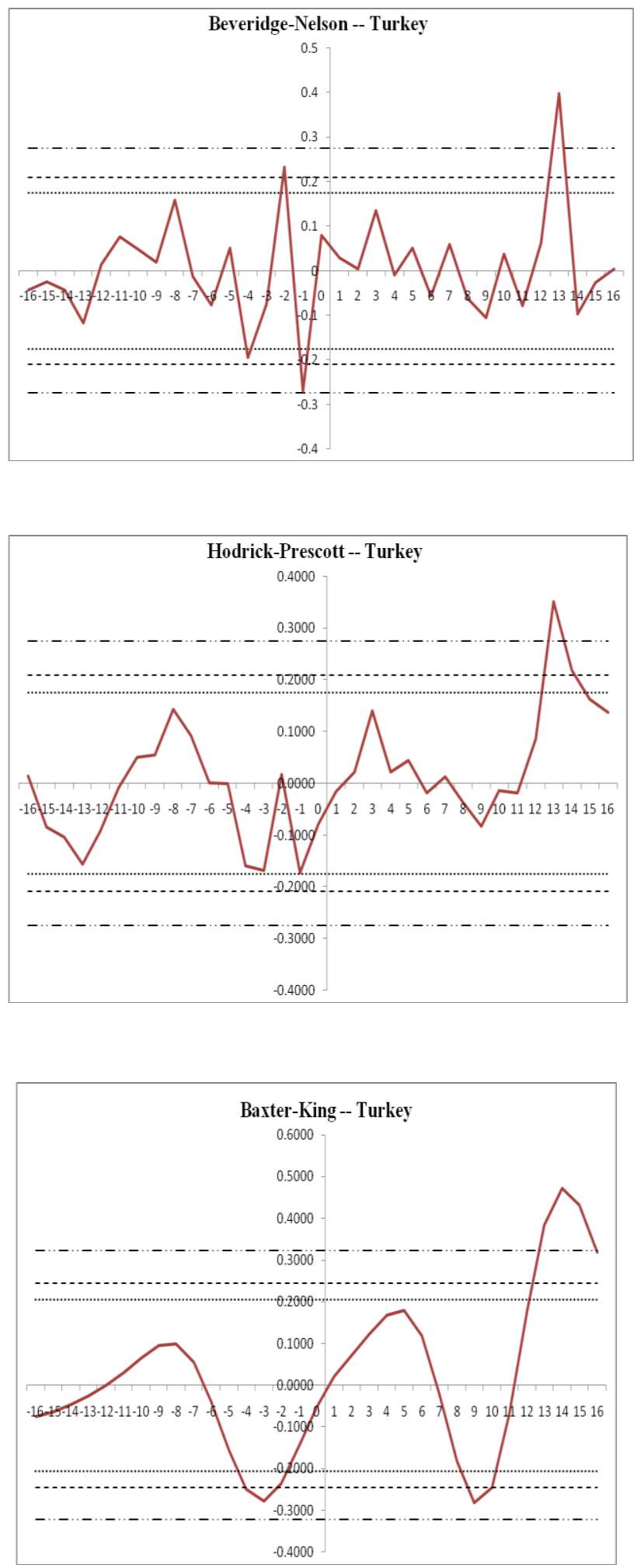

corr(Remittances,GermanyGDP)
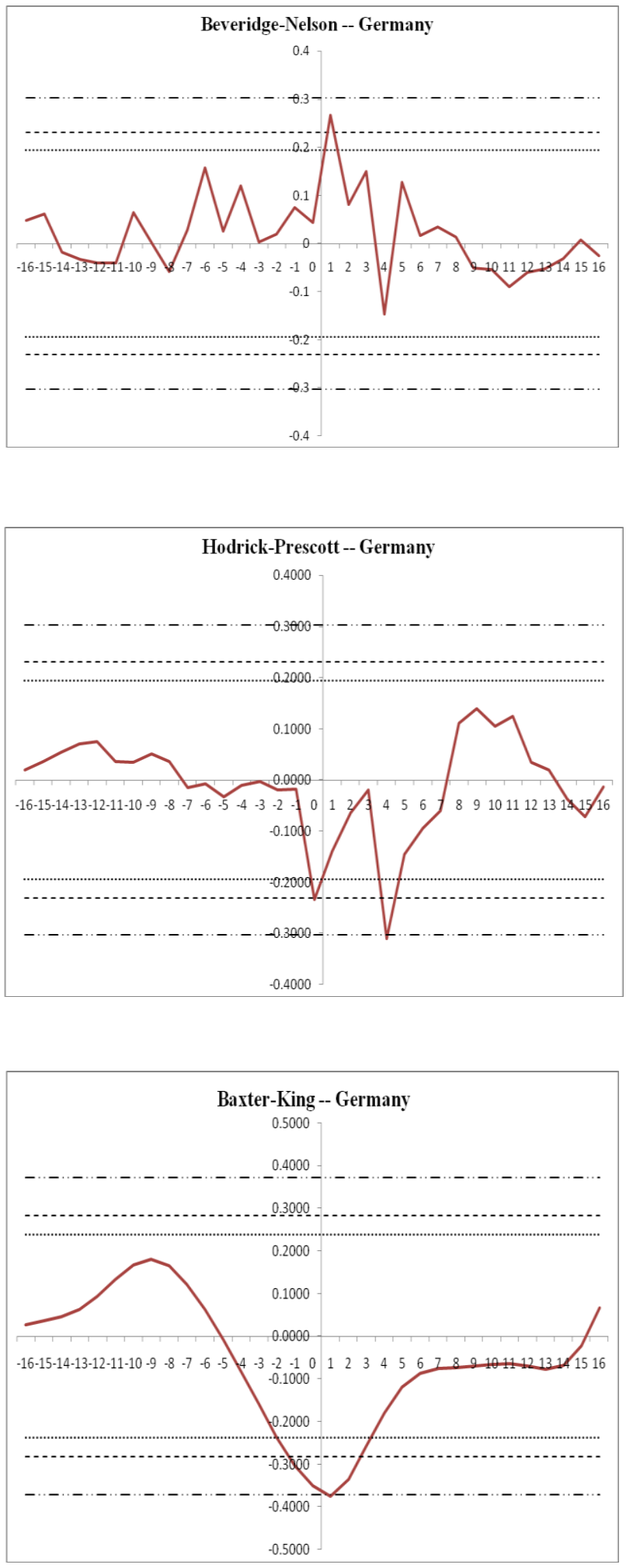
corr(Remittances,TurkeyGDP)
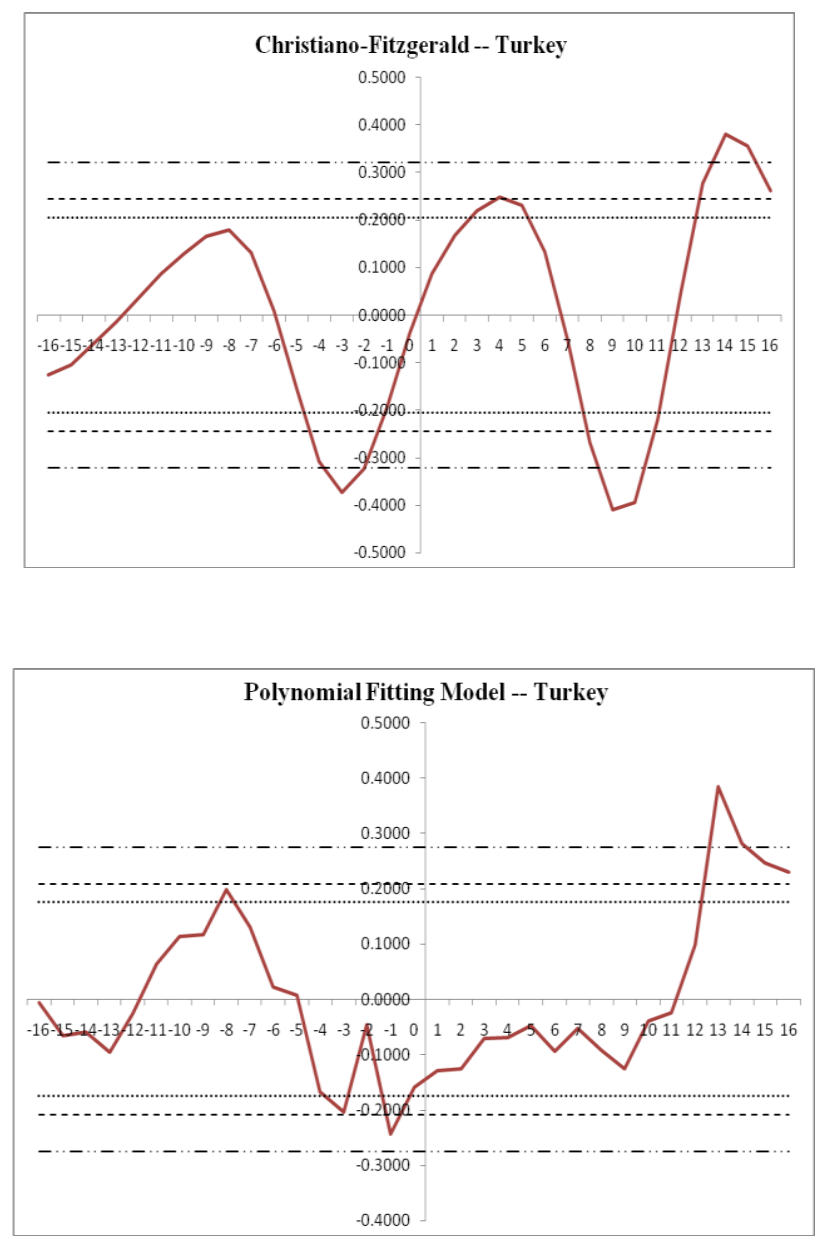

corr(Remittances,GermanyGDP)
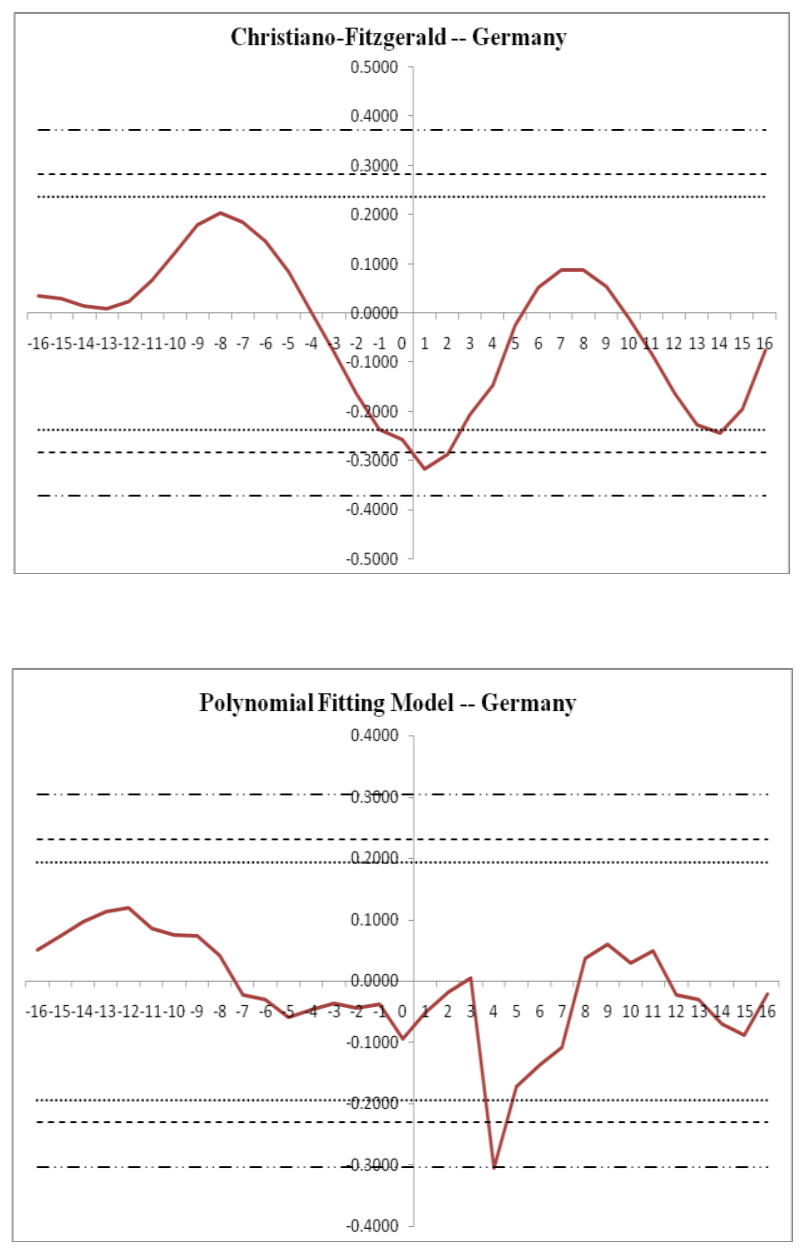
Figure 11. Cross-correlation analysis for Mexico with structural breaks in remittances

One Break: IRCA
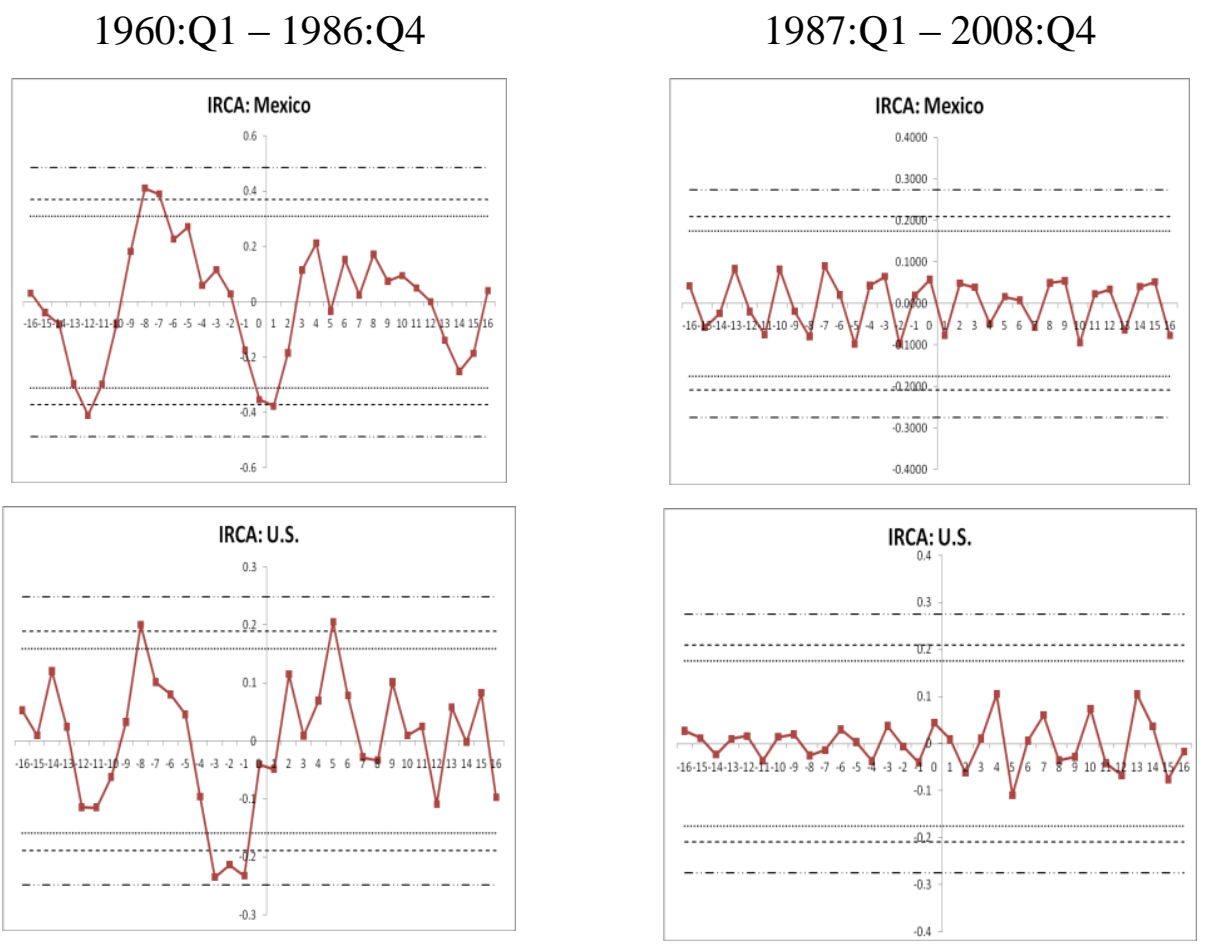

One Break: Banxico
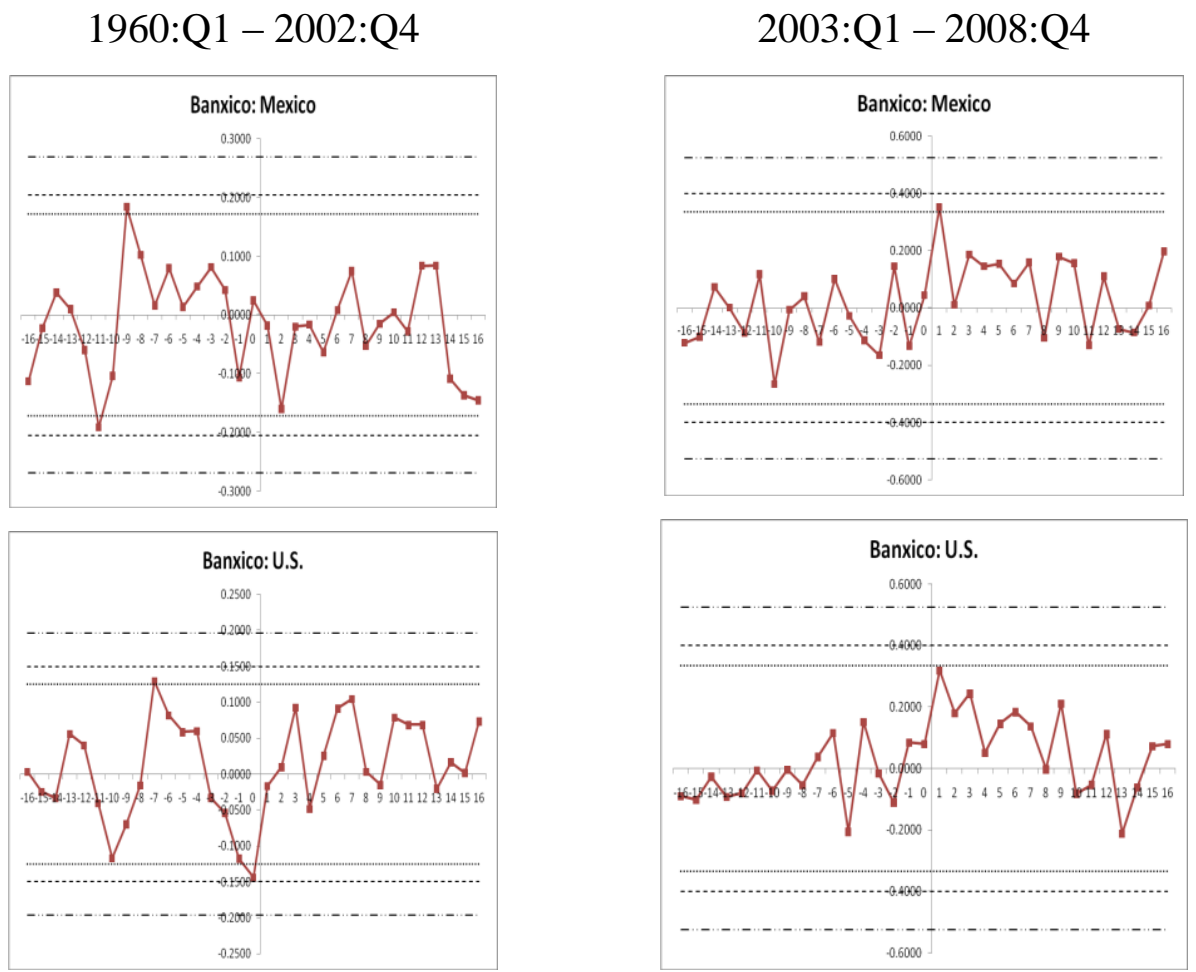
Two Breaks: IRCA \& Banxico
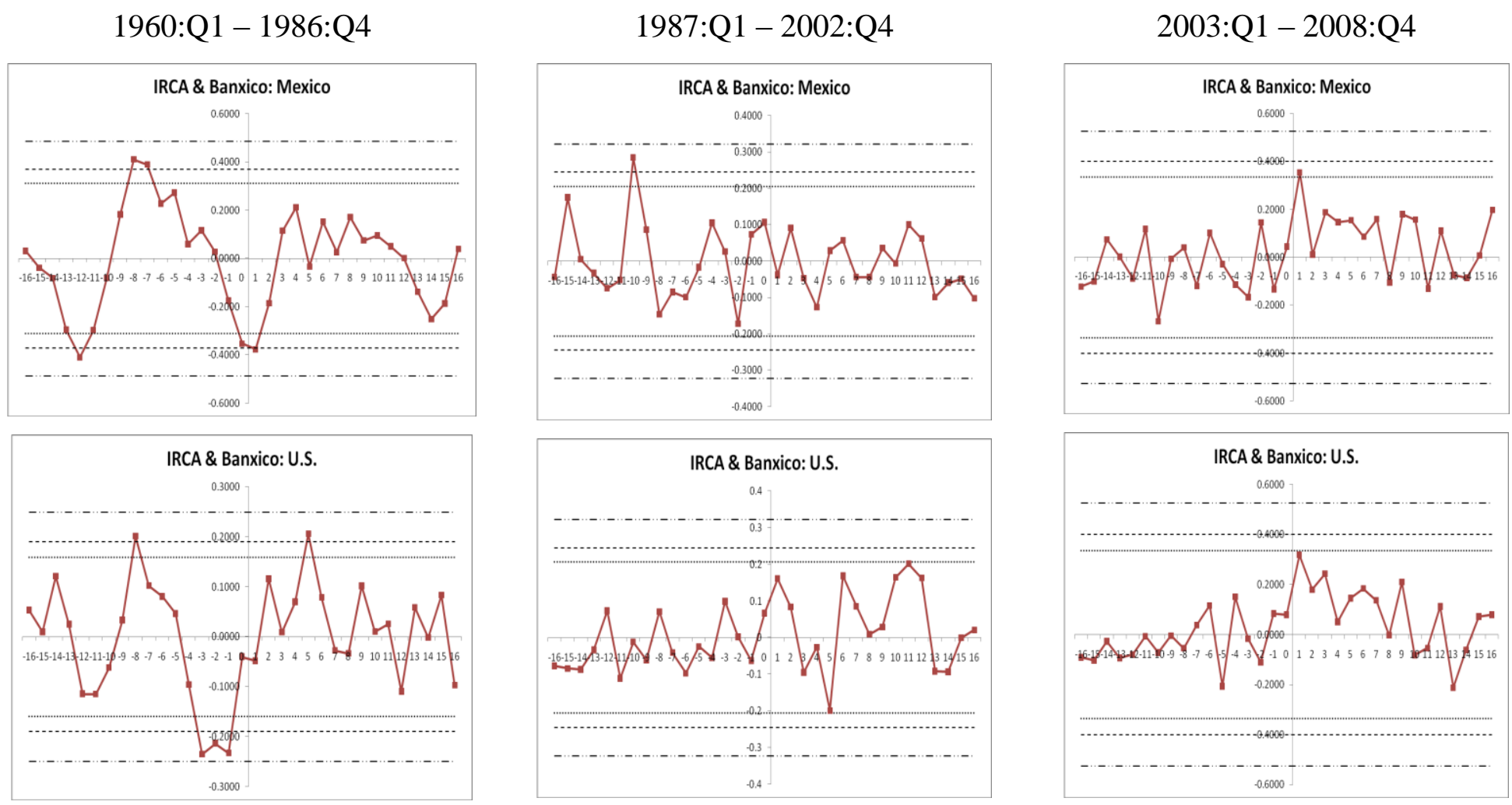